\title{
Modeling Neutral Densities Downstream of a Gridded Ion Thruster
}

George C. Soulas

Glenn Research Center, Cleveland, Ohio 


\section{NASA STI Program . . . in Profile}

Since its founding, NASA has been dedicated to the advancement of aeronautics and space science. The NASA Scientific and Technical Information (STI) program plays a key part in helping NASA maintain this important role.

The NASA STI Program operates under the auspices of the Agency Chief Information Officer. It collects, organizes, provides for archiving, and disseminates NASA's STI. The NASA STI program provides access to the NASA Aeronautics and Space Database and its public interface, the NASA Technical Reports Server, thus providing one of the largest collections of aeronautical and space science STI in the world. Results are published in both non-NASA channels and by NASA in the NASA STI Report Series, which includes the following report types:

- TECHNICAL PUBLICATION. Reports of completed research or a major significant phase of research that present the results of NASA programs and include extensive data or theoretical analysis. Includes compilations of significant scientific and technical data and information deemed to be of continuing reference value. NASA counterpart of peer-reviewed formal professional papers but has less stringent limitations on manuscript length and extent of graphic presentations.

- TECHNICAL MEMORANDUM. Scientific and technical findings that are preliminary or of specialized interest, e.g., quick release reports, working papers, and bibliographies that contain minimal annotation. Does not contain extensive analysis.

- CONTRACTOR REPORT. Scientific and technical findings by NASA-sponsored contractors and grantees.
- CONFERENCE PUBLICATION. Collected papers from scientific and technical conferences, symposia, seminars, or other meetings sponsored or cosponsored by NASA.

- SPECIAL PUBLICATION. Scientific, technical, or historical information from NASA programs, projects, and missions, often concerned with subjects having substantial public interest.

- TECHNICAL TRANSLATION. Englishlanguage translations of foreign scientific and technical material pertinent to NASA's mission.

Specialized services also include creating custom thesauri, building customized databases, organizing and publishing research results.

For more information about the NASA STI program, see the following:

- Access the NASA STI program home page at http://www.sti.nasa.gov

- E-mail your question via the Internet to help@ sti.nasa.gov

- Fax your question to the NASA STI Help Desk at 443-757-5803

- Telephone the NASA STI Help Desk at 443-757-5802

- Write to: NASA Center for AeroSpace Information (CASI) 7115 Standard Drive Hanover, MD 21076-1320 


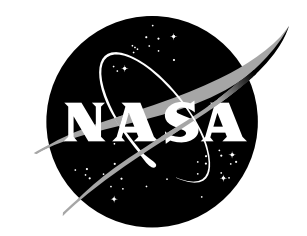

\section{Modeling Neutral Densities Downstream of a Gridded Ion Thruster}

George C. Soulas

Glenn Research Center, Cleveland, Ohio

Prepared for the

49th Joint Propulsion Conference and Exhibit

cosponsored by the AIAA, ASME, SAE, and ASEE

Nashville, Tennessee, July 25-28, 2010

National Aeronautics and

Space Administration

Glenn Research Center

Cleveland, Ohio 44135 
This report contains preliminary findings, subject to revision as analysis proceeds.

Level of Review: This material has been technically reviewed by technical management.

Available from

NASA Center for Aerospace Information

7115 Standard Drive

Hanover, MD 21076-1320
National Technical Information Service 5301 Shawnee Road Alexandria, VA 22312

Available electronically at http://gltrs.grc.nasa.gov 


\title{
Modeling Neutral Densities Downstream of a Gridded Ion Thruster
}

\author{
George C. Soulas \\ National Aeronautics and Space Administration \\ Glenn Research Center \\ Cleveland, Ohio 44135
}

\begin{abstract}
The details of a model for determining the neutral density downstream of a gridded ion thruster are presented. An investigation of the possible sources of neutrals emanating from and surrounding a NEXT ion thruster determined that the most significant contributors to the downstream neutral density include discharge chamber neutrals escaping through the perforated grids, neutrals escaping from the neutralizer, and vacuum facility background neutrals. For the neutral flux through the grids, near- and far-field equations are presented for rigorously determining the neutral density downstream of a cylindrical aperture. These equations are integrated into a spherically-domed convex grid geometry with a hexagonal array of apertures for determining neutral densities downstream of the ion thruster grids. The neutrals escaping from an off-center neutralizer are also modeled assuming diffuse neutral emission from the neutralizer keeper orifice. Finally, the effect of the surrounding vacuum facility neutrals is included and assumed to be constant. The model is used to predict the neutral density downstream of a NEXT ion thruster with and without neutralizer flow and a vacuum facility background pressure. The impacts of past simplifying assumptions for predicting downstream neutral densities are also examined for a NEXT ion thruster.
\end{abstract}

\section{Nomenclature}

a $\quad y$-intercept in the non-dimensional wall flux equation

$\mathrm{A}_{\mathrm{o}} \quad$ reservoir particle emission area

$\mathrm{A}_{\mathrm{w}} \quad$ cylindrical wall particle emission area

b slope in the non-dimensional wall flux equation

c neutral particle mean thermal speed

$\mathrm{D}(\gamma, \beta) \quad$ normalized neutral density distribution upstream of the thruster grids

e charge of an electron (i.e., $1.602 \times 10^{-19} \mathrm{C}$ ),

$\mathrm{f}(\mathrm{v}) \quad$ Maxwell-Boltzmann speed distribution function

$\mathrm{F}_{\text {oa }} \quad$ accelerator grid open area fraction

$\mathrm{F}_{\mathrm{scrn}} \quad$ neutral density correction factor to account for the screen grid (i.e., 0.93 for the NEXT grids)

$\mathrm{J}_{\mathrm{b}} \quad$ thruster beam current

$\mathrm{J}^{++} / \mathrm{J}^{+} \quad$ discharge chamber total doubly-to-singly-charged ion current ratio

$\mathrm{k} \quad$ hexagon side number

$\mathrm{k}_{\mathrm{B}} \quad$ Boltzmann's constant (i.e., $1.3804 \times 10^{-23} \mathrm{~J} / \mathrm{K}$ )

$\mathrm{K}_{\mathrm{c}} \quad$ transmission probability of neutrals through an accelerator grid aperture

$\mathrm{L} \quad$ length between the surface normal of $\mathrm{dA}_{\mathrm{o}}$ to the downstream neutral density location

$1_{\mathrm{cc}} \quad$ grid aperture center-to-center spacing

$\mathrm{L}_{\text {grid }} \quad$ length between the grid neutral emission site to the downstream neutral density location

$\mathrm{L}_{\text {neut }} \quad$ length between the neutralizer neutral emission area to the downstream neutral density location

$\mathrm{m} \quad$ number of apertures along the side of a hexagonal array of holes

$\dot{\mathrm{m}}_{\mathrm{d}} \quad$ total flow rate into the discharge chamber

$\mathrm{m}_{\mathrm{n}} \quad$ molecular mass of the neutral gas particle

$\dot{\mathrm{m}}_{\text {neut }} \quad$ neutralizer mass flow rate

$\mathrm{n} \quad$ downstream neutral density

$\mathrm{n}_{\mathrm{far}} \quad$ far-field equation for the downstream neutral density from an aperture

$\mathrm{n}_{\text {far-gridsum }}$ far-field equation for the downstream neutral density from a grid by summing individual aperture contributions

$\mathrm{n}_{\text {far-gridint }}$ far-field equation for the downstream neutral density from a grid by integration of the grid surface

$\mathrm{n}_{\text {grid }}$ downstream neutral density from discharge chamber neutrals escaping through the grids equation for the downstream neutral density from an aperture in the near- and far-fields 


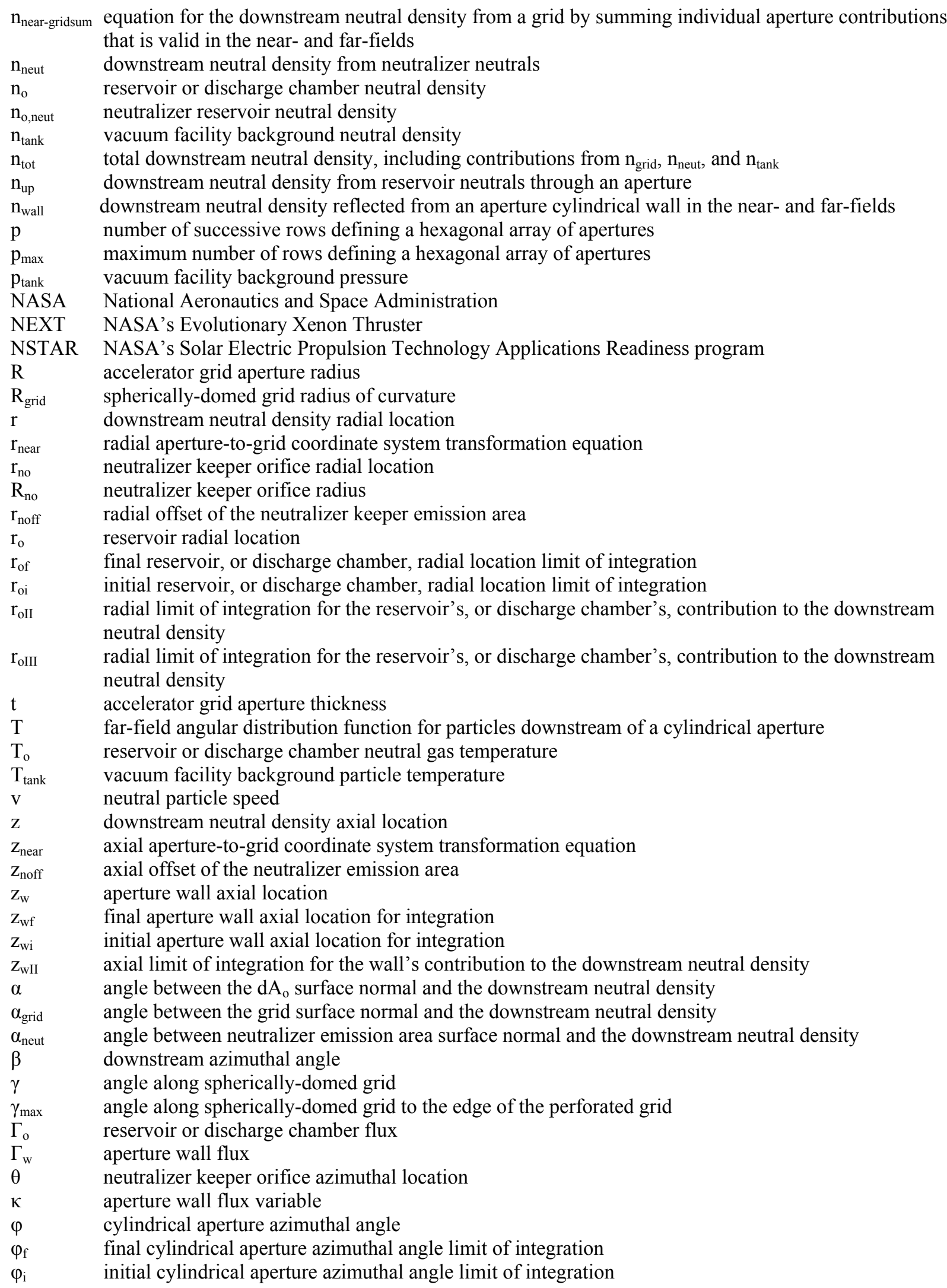


$\varphi_{\mathrm{oI}} \quad$ angular limit of integration for the reservoir's, or discharge chamber's, contribution to the downstream neutral density

$\varphi_{\text {omax }} \quad$ angular limit of integration for the reservoir's, or discharge chamber's, contribution to the downstream neutral density

$\varphi_{\mathrm{wI}} \quad$ angular limit of integration for the wall's contribution to the downstream neutral density

$\varphi_{\mathrm{wt}} \quad$ angular limit of integration for the wall's contribution to the downstream neutral density

$\omega_{\mathrm{o}} \quad$ solid angle from $\mathrm{dA}_{\mathrm{o}}$

$\omega_{\mathrm{w}} \quad$ solid angle from $\mathrm{dA}_{\mathrm{w}}$

Subscripts and Superscripts

- $\quad$ non-dimensionalized value (dimensions are divided by $\mathrm{R}$, densities by $\mathrm{n}_{\mathrm{o}}$, and fluxes by $\Gamma_{\mathrm{o}}$ )

o reservoir, or discharge chamber

W aperture wall

\section{Introduction}

The successful demonstration of the NSTAR (NASA's Solar Electric Propulsion Technology Applications Readiness program) ion thruster on the Deep Space 1 mission and its subsequent use on the Dawn spacecraft have demonstrated the utility and reliability of ion thrusters for NASA's deep space missions (Refs. 1 to 5). As a direct result of this success, NASA continued the development of ion propulsion technology by investing in NASA's Evolutionary Xenon Thruster, or NEXT, which represents a next-generation ion propulsion system (Ref. 6). The objective of the NEXT project is to advance this next generation ion propulsion technology to NASA Technology Readiness Level 5, with significant progress towards Level 6, to support NASA Science Mission Directorate missions (Ref. 7). The NEXT program is developing an advanced ion propulsion system, that includes, in part, a high performance, $7 \mathrm{~kW}$ ion thruster with a spherically-domed beam extraction grid system with a chord diameter of $36 \mathrm{~cm}$.

Although the NEXT ion thruster exhibits high propellant utilization efficiencies throughout its throttling range, some un-ionized propellant, or neutrals, will inevitably escape the ion thruster's discharge chamber and neutralizer. For example, some neutrals will escape from the thruster discharge chamber through the grid apertures and expand into the vacuum of space. Some of these neutrals can undergo charge-exchange with the beam ion plume to create slow-moving charge-exchange ions. These charge-exchange ions are subsequently directed by potentials within the ion beam and charge-exchange plasmas away from the thrust axis and possibly towards spacecraft surfaces. Although the energies of these ions are low, modeling of the charge-exchange plasma is typically conducted to understand where these charge-exchange ions are directed and to assess their possible impact on the spacecraft. Properly modeling charge-exchange production requires an accurate understanding of the neutral density distribution downstream of and surrounding an ion thruster.

In addition to charge-exchange plasma effects on the spacecraft, the neutrals escaping from the thruster can also affect plasma diagnostics' measurements. For example, measurements of the doubly-charged beam ion current relative to the singly-charge current are affected by differences in charge-exchange cross-sections (Ref. 8). Specifically, the charge-exchange cross-section for singly-charged ions is much larger than that of doubly-charged ions (Ref. 9). This can lead to exaggerated doubly-to-singly-charged ion current ratios when measured far downstream of the ion thruster and at high background pressures (Ref. 8). Properly modeling this charge-exchange effect again requires an accurate understanding of the neutral density distribution downstream of the ion thruster.

Many past studies have modeled the downstream neutral density emanating from an ion thruster. Unfortunately, most studies made simplifying assumptions that limited the utility of their models. These simplifying assumptions ignored the effect of the grid shape and the neutral efflux "beaming" effect of individual apertures of finite thickness, where thicker aperture walls direct more escaping neutrals along the aperture centerline (Refs. 10 and 11). Very early studies either treated the thruster as a point source for far-field analyses or merely assumed that the thruster was a flat surface with neutral particle emission throughout the surface, allowing for a simpler analytical expression to be used (Refs. 12 and 13). A large number of studies modeled the downstream neutral density using an analytical expression that merely assumed a neutrals point source upstream of the thruster grids (Refs. 14 to 21). Another study used an analytical expression that assumed that neutrals were emitted from a flat disk diffusely (Ref. 22). And yet other analyses utilized a Monte Carlo Particle-in-Cell technique to model the neutral efflux from ion thruster (Refs. 23 to 26). Such a technique has the benefit of including the impacts of charge exchange on the velocity distribution of the neutral efflux, for example, but computational difficulties with this technique led to 
simplifications that included computational boundaries that assumed a flat grid without individual apertures. The failure of all aforementioned studies to capture the effect of the grid shape and the "beaming" effect of individual apertures reduced the accuracy of the modeled results and limited the utility of the models to the far-field.

Three studies did include the effect of the grid shape and two studies included neutral efflux from individual apertures (Refs. 27 to 29). Unfortunately, two studies did not accurately model the neutral efflux "beaming" effect of individual apertures (Refs. 27 and 28). The other study correctly captured this neutral "beaming" effect (Ref. 29). However, all three studies did not present the equations necessary to recreate the models.

In addition to these simplifying assumptions, almost all of the aforementioned studies assumed that neutrals were only emitted through the thruster grids (Refs. 12 to 27 and 29). So, most of the studies neglected the contribution of the neutral efflux from the thruster's neutralizer and the possible contribution of downstream reflections from other thruster surfaces.

This paper will present the details of a model for determining the neutral density downstream of a gridded ion thruster. The model will include the effects of the grid's spherical shape and the neutral efflux "beaming" through cylindrical apertures in both the near- and far-fields. The first section will examine all sources for neutrals emanating from an ion thruster. The following section will present near- and far-field equations for modeling neutral densities emanating from a discharge chamber through cylindrical apertures based on equations derived in other studies (Refs. 10,11, and 30). These equations will then be integrated into the complex perforated grid geometry and this, along with the neutral efflux from the neutralizer, will be used to model neutral densities downstream of an ion thruster. The model will then be used to predict the neutral density downstream of a NEXT ion thruster with and without neutralizer flow and a vacuum facility background pressure. Finally, the impact of past simplifying assumptions for predicting downstream neutral densities will be assessed.

\section{Sources of Neutrals From and Surrounding an Ion Thruster}

Figure 1 shows sketches of a typical ion thruster with the various sources of neutrals that can emanate from and surround the thruster. As shown in the sketch, the sources of neutrals downstream of an ion thruster originate from the following thruster regions:

1. un-ionized propellant escaping from the discharge chamber through:

a. the apertures of the perforated grids;

b. the thruster's plasma screen;

c. the gap between the front mask and accelerator grid; and

2. un-ionized propellant escaping from the neutralizer;

3. vacuum facility background neutrals.
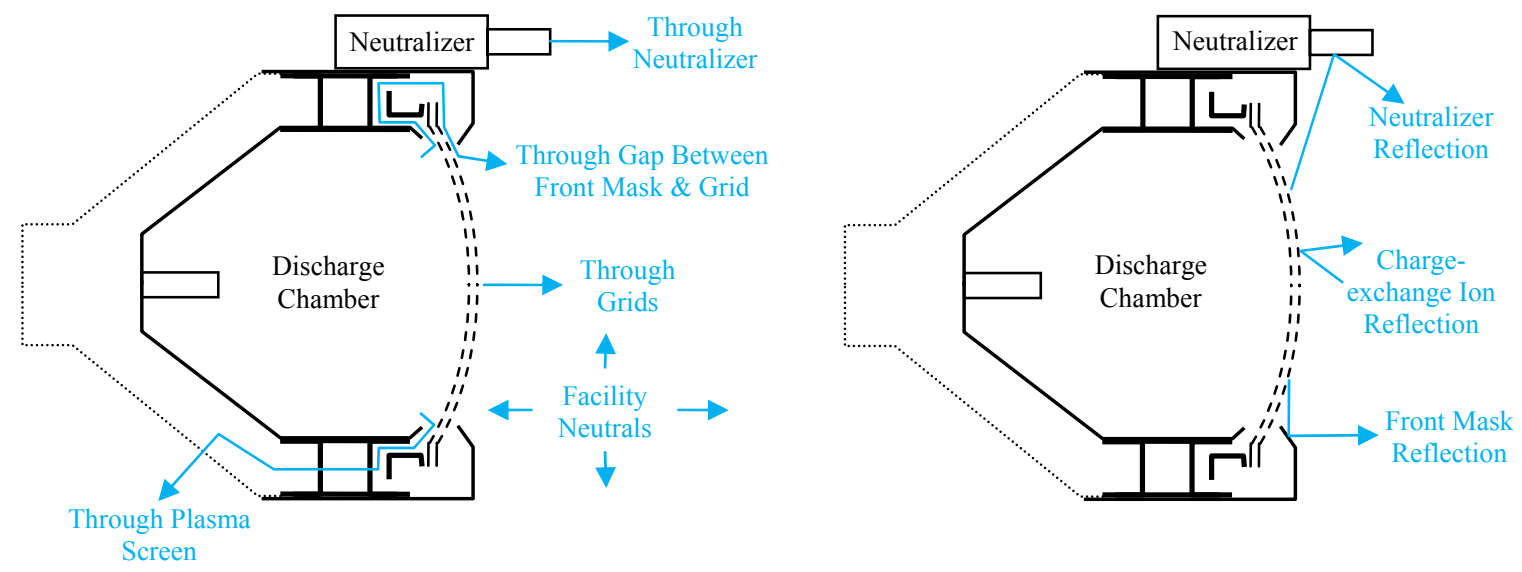

Figure 1.-Unionize propellant escape paths from the thruster (right sketch) and downstream reflections of un-ionized propellant escaping from through the grids (left sketch). 
Also important are the reflections that un-ionized neutrals make after they exit the thruster, as shown in Figure 1. It will be shown that the discharge neutrals escaping through the grids are the most significant source of neutrals from the thruster. The downstream reflections of these neutrals include:

1. neutrals reflected from the front mask;

2. neutrals reflected from the neutralizer; and

3. ions that impact the accelerator grid downstream surface and aperture walls and leave as neutrals.

As the lists above and Figure 1 demonstrate, there are a numerous regions from an ion thruster where neutral particles can be ejected.

Fortunately, there are two considerations that can reduce the complexity of determining downstream neutral densities. The first is related to the neutral densities within and surrounding the thruster. Ion thrusters typically operate at very low neutral densities. For a NEXT ion thruster operating at full power, for example, the neutral density within the discharge chamber is estimated to be about $2.5 \times 10^{18} \mathrm{~m}^{-3}$. At this low particle density, the mean free path for neutral-to-neutral collisions is about $6 \mathrm{~cm}$, which is $1 / 6$ of the NEXT discharge chamber chord diameter and about 50x larger than an accelerator aperture diameter. Downstream of the thruster and within a vacuum facility at a $6.7 \times 10^{-3} \mathrm{~Pa}\left(5 \times 10^{-6}\right.$ torr $)$ background pressure, the mean free path for neutral-to-neutral collisions is about $93 \mathrm{~cm}$. Such large mean free paths define a rarified gas flow regime referred to as free molecular flow. In this flow regime, particle-to-particle collisions are so rare that they can be neglected. The benefit of modeling this regime is that the resulting downstream neutral density from the various neutral particle sources (shown in Fig. 1) can be modeled separately, and the resulting fluxes and densities can be added together to determine the total downstream neutral density.

Only within the neutralizer, where pressures can reach as high as about 67 torr at full power for the NEXT neutralizer (Ref. 31), are the mean free paths for neutral-to-neutral collisions small enough for these collisions to be significant (i.e., mean free paths of about $3 \times 10^{-6} \mathrm{~cm}$ at full power within the cathode insert region). However, these neutral-to-neutral mean free paths increase rapidly as the gas is ionized (and hence the neutral population decreases) and the neutral gas plume expands into vacuum. Because the neutral density downstream of and surrounding the thruster is desired, collisional effects within the neutralizer and immediately downstream of the neutralizer cathode orifice can also be ignored and the downstream free molecular flow conditions can be considered.

The second consideration that can reduce the complexity of determining downstream neutral densities is the relative contribution of each neutral source and escape path. Although neutrals can escape from many regions of an ion thruster, some of the aforementioned emission sites can be neglected without any significant loss of accuracy. Although there are three escape paths for neutrals to leave the discharge chamber, the vast majority of particles will exit through the grid apertures. This is due to two reasons 1) the open area between the grids and discharge chamber is only about 11 percent that of the accelerator grid open area for a NEXT thruster; and 2) the transmission probability through the grid apertures is much higher. Regarding the latter, the escape paths from the discharge chamber to the plasma screen and front mask are typically significantly tortuous, involving multiple wall collisions before escaping, and exhibiting no direct line-of-sight. However, the escape path through the accelerator grid apertures is more direct and, as a result, will have a much higher transmission probability. The transmission probabilities through the front mask and plasma screen escape paths were crudely estimated for a NEXT ion thruster. This was done by treating the transmission between components within the thruster independently and assuming that the entrance conditions of the neutrals for each component was random (Ref. 32). In addition, other simplifying assumptions were made to handle bends and elbows, as well as the shapes through which neutrals were flowing. The total amount of propellant leaking through the front mask and plasma screen was estimated to be about 1 percent of that escaping through the accelerator grid apertures. Of this 1 percent neutral loss, most escaped through the plasma screen. Because this represents such a small amount of the total leakage, this study will neglect neutrals escaping through the front mask gap and plasma screen.

For a typical NEXT ion thruster, the accelerator current at full power is about $14 \mathrm{~mA}$ while the neutral loss rate from the discharge chamber is estimated to be 0.51 equivalent Amperes (Ref. 31). So, the total flux rate of neutralized accelerator current is only 2.7 percent that of the discharge chamber neutral loss rate. In addition to this, the accelerator current collected by the accelerator grid is a combination of charge-exchange ions collected on the downstream grid and within the accelerator aperture walls. While those ions collected on the downstream accelerator surface would be expected to contribute directly to the downstream neutral density, those collected 
within the aperture barrel would not necessarily do so. This is because a portion of those ions would be reflected upstream and could, therefore, re-enter the discharge chamber. This further reduces the contribution of reflected charge-exchange ions on the downstream neutral density. As a result, the total flux rate of neutralized accelerator current that contributes to the downstream neutral density is less than 2.7 percent that of the discharge chamber neutral loss rate. Because of this small contribution, ions that impact the accelerator grid downstream surface and aperture walls and leave as neutrals will also be neglected in this study.

To determine if neutralizer and front mask reflections are significant, the flux of neutrals that escape from the grid apertures and impinge on the neutralizer and front mask was conservatively estimated. It was determined that the neutralizer and front mask intercept less than 0.2 percent and less than 0.9 percent, respectively, of the total neutral loss from the discharge chamber. Although the reflected neutrals can have a noticeable effect on the neutral density very close to the neutralizer and front mask surfaces, the effect further from these surfaces will be negligible. The effect of reflected neutrals from the neutralizer and front mask will, therefore, be neglected in this study.

Vacuum facility background neutrals cannot typically be ignored. Within a vacuum facility at a $6.7 \times 10^{-3} \mathrm{~Pa}$ $\left(5 \times 10^{-6}\right.$ torr) background pressure, the neutral density would be about $1.6 \times 10^{17} \mathrm{~m}^{-3}$, which is 6 percent that of the NEXT discharge chamber density operating at full power. More importantly, however, the background neutral density would be expected to be constant far downstream of an ion thruster, where the density of neutrals emanating from a thruster would be expected to be considerably lower than discharge chamber neutral densities. The effect of vacuum facility background neutrals will, therefore, be included in this study.

Neutralizer flow rates are typically large in comparison to the discharge chamber neutral loss rate. For a NEXT thruster operating at full power, the neutralizer flow rate is $4.01 \mathrm{sccm}$. Although some of this neutralizer flow will exit the neutralizer as ionized gas, the majority is expected to exit as un-ionized propellant. Mikellides modeled a NEXT neutralizer during thruster operation at full power (Ref. 33). He found that the neutralizer neutral loss rate was $2.8 \mathrm{sccm}$ during full power operation (Ref. 34). This represents 40 percent of the discharge chamber neutral loss rate. Because of the significance of this neutral loss contribution, the neutral loss from the neutralizer will be modeled in this study.

One other source of neutrals, not shown in Figure 1 and neglected in this study, is the fast-moving neutrals created by charge-exchange between downstream neutrals and beam ions. Unfortunately, this requires knowledge of the spatial distribution of beam ion current density, which is beyond the scope of this study. Because of operation in the free molecular flow regime, however, the distribution of these neutrals can be determined by later modeling and the result added to that of this study, assuming the change in total neutral density is negligibly small.

Table 1 summarizes the various neutral escape and reflection sites, their relative contributions, and whether they are modeled in this study. As the table shows, the significant contributors to the downstream neutral density include: 1) the neutral flow from the discharge chamber through the grid apertures; 2) neutrals from the neutralizer; and 3 ) background vacuum facility neutrals. The next section will develop the equations for modeling the downstream neutral density from these neutral sources.

TABLE 1.-SUMMARY OF NEUTRAL PARTICLE SOURCES, THEIR RELATIVE CONTRIBUTIONS, AND WHETHER THEY ARE MODELED IN THIS STUDY

\begin{tabular}{|l|l|c|}
\hline \multicolumn{1}{|c|}{ Neutral particle source } & \multicolumn{1}{c|}{ Relative contribution ${ }^{\text {a }}$} & Modeled in this study? \\
\hline $\begin{array}{l}\text { Discharge chamber-Through grid } \\
\text { apertures }\end{array}$ & 99 percent of discharge chamber neutral loss rate & Nes \\
\hline $\begin{array}{l}\text { Discharge chamber-Through gap } \\
\text { between front mask and grid }\end{array}$ & $\sim 0.2$ percent of discharge chamber neutral loss rate \\
\hline $\begin{array}{l}\text { Discharge chamber-Through plasma } \\
\text { screen }\end{array}$ & $\sim 0.8$ percent of discharge chamber neutral loss rate & No \\
\hline Neutralizer & 40 percent of discharge chamber neutral loss rate & Yes \\
\hline Facility background neutrals & 6 percent of discharge chamber neutral density & Yes \\
\hline Reflected accelerator current & 2.7 percent of discharge chamber neutral loss rate & No \\
\hline Reflected from neutralizer & $\begin{array}{l}<0.2 \text { percent of discharge chamber neutral loss } \\
\text { rate reflected }\end{array}$ & No \\
\hline Reflected from front mask & $\begin{array}{l}<0.9 \text { percent of discharge chamber neutral loss } \\
\text { rate reflected }\end{array}$ & No \\
\hline From charge-exchange with beam ions & Beyond scope of this study & No \\
\hline
\end{tabular}

${ }^{a}$ Assumes a NEXT ion thruster operating at full power with a background pressure of $5 \times 10^{-6}$ torr. 


\section{Model Development}

The following sections will develop the equations necessary to determine the neutral density downstream of an ion thruster. The first section lists the assumptions and fundamental equations used to determine the downstream neutral density. Far- and near-field equations for determining the neutral density downstream of a cylindrical aperture are presented thereafter. The subsequent sections develop the base equations for determining downstream neutral density from a spherically-dome convex grid with a hexagonal array of apertures, an off-center neutralizer, and the surrounding vacuum facility neutrals.

\section{A. Assumptions and Fundamental Equations}

The equations used in the following sections are based on the fundamental equations presented within this section. The assumptions used to develop these equations include the following:

1. the neutral density is sufficiently low that free molecular flow conditions exist throughout the modeled domain;

2. neutrals from a reservoir (e.g., the discharge chamber) have a Maxwell-Boltzmann speed distribution;

3. equilibrium conditions exist, so that the rate of neutrals leaving the reservoir is equal to the rate of neutrals fed into the reservoir;

4. all wall reflections are diffuse;

5. neutral adsorption onto the walls and surface diffusion are negligible; and

6. wall temperatures are equal to the neutral particle temperature.

The geometric relation between a differential element from a neutral particle emission site (i.e., a wall or the upstream reservoir, such as the discharge chamber) and the downstream neutral density location is shown in Figure 2. The variable $\alpha$ is the angle between the neutral emission site surface normal from the differential emitting area, $\mathrm{dA}_{\mathrm{o}}$, to the location of the downstream neutral density, $\mathrm{n}$. The variable $\mathrm{L}$ is the distance between the differential emitting area and downstream density.

The downstream neutral density from a reservoir of neutrals can be solved by starting with the MaxwellBoltzmann phase space speed distribution function (Ref. 35). Because equilibrium conditions are assumed, the speed distribution function, $\mathrm{f}(\mathrm{v})$, is independent of position (i.e., neutral velocities are isotropic). So, the neutral density downstream of an orifice to a reservoir is:

$$
n=\iiint_{\infty} n_{0} \cdot f(v) \cdot d^{3} v=\int_{0}^{\infty} \int_{\omega_{0}} f(v) \cdot n_{o} \cdot d \omega_{0} \cdot d v=\int_{0}^{\infty} f(v) \cdot d v \cdot \int_{\omega_{0}} n_{o} \cdot d \omega_{0}
$$

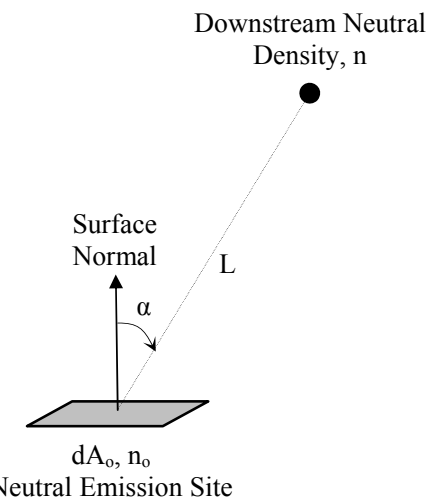

Figure 2.-Geometric relation between a neutral emission site and the downstream neutral density. 
Here, $n_{o}$ is the neutral density within the reservoir and the differential solid angle, $d \omega_{0}$, is given by:

$$
\mathrm{d} \omega_{\mathrm{o}}=\frac{\mathrm{dA}_{\mathrm{o}} \cdot \cos (\alpha)}{\mathrm{L}^{2}}
$$

The first integral in Equation (1) can be shown to be $1 /(4 \cdot \pi)$, so substituting this and Equation (2) into Equation (1) yields:

$$
\mathrm{n}=\frac{1}{4 \cdot \pi} \cdot \int_{\mathrm{A}_{\mathrm{o}}} \mathrm{n}_{\mathrm{o}} \cdot \frac{\cos (\alpha)}{\mathrm{L}^{2}} \cdot \mathrm{dA}_{\mathrm{o}}
$$

This equation is in a form that is useful for solving for the downstream neutral density when the emission site is the reservoir. When the emission site is a wall, it is more useful to re-express Equation (3) using a particle flux. This is done by noting that the flux in any one direction from a reservoir or diffusely-emitting surface is given by:

$$
\Gamma_{\mathrm{o}, \mathrm{w}}=\frac{\mathrm{n}_{\mathrm{o}, \mathrm{w}} \cdot \mathrm{c}}{4}
$$

where $\mathrm{c}$ is the mean thermal speed of the neutrals and the " $\mathrm{w}$ " subscript denotes a wall while the "o" subscript denotes a reservoir. Solving Equation (4) for $\mathrm{n}_{\mathrm{o}}$ and substituting this into Equation (1) yields:

$$
\mathrm{n}=\iiint_{\infty} \frac{4 \cdot \Gamma_{\mathrm{w}}}{\mathrm{c}} \cdot \mathrm{f}(\mathrm{v}) \cdot \mathrm{d}^{3} \mathrm{v}=\int_{0}^{\infty} \mathrm{f}(\mathrm{v}) \cdot \mathrm{dv} \cdot \int_{\omega_{\mathrm{w}}} \frac{4 \cdot \Gamma_{\mathrm{w}}}{\mathrm{c}} \cdot \mathrm{d} \omega_{\mathrm{w}}
$$

Note that $\Gamma_{\mathrm{w}}$ appears within the second integral because the wall flux will be shown to be a function of the location on the wall. Substituting Equation (2) into Equation (5) yields:

$$
\mathrm{n}=\frac{1}{\mathrm{c} \cdot \pi} \cdot \int_{\mathrm{A}_{\mathrm{w}}} \Gamma_{\mathrm{w}}\left(\mathrm{A}_{\mathrm{w}}\right) \cdot \frac{\cos (\alpha)}{\mathrm{L}^{2}} \cdot \mathrm{dA}_{\mathrm{w}}
$$

which is in a form that is useful for solving the downstream neutral density when a reflecting wall is the emission site.

\section{B. Equations for the Neutral Density Downstream of a Single Cylindrical Aperture}

The following sections will develop the equations for modeling the neutral density surrounding a grid cylindrical aperture. Two sets of equations will be presented. The first is an expression that was initially derived by Clausing and is only valid in the far-field (i.e., far enough from an aperture to consider it a point source) (Refs. 10 and 11). The second is a series of equations that can be used to rigorously determine neutral density within and downstream of a cylindrical aperture both in the near- and far-fields.

The NEXT ion thruster utilizes a two grid system for accelerating beam ions. The upstream, or screen, grid is a thin grid with nearly cylindrical apertures and a high open area fraction. The thin screen grid thickness enhances thruster perveance while the small surface area reduces the likelihood that a discharge chamber ion will strike it and recombine with an electron, thus improving discharge chamber electrical efficiency. On the other hand, the downstream, or accelerator, grid is a thick grid with nearly cylindrical apertures and a much smaller open area fraction. The thicker accelerator grid enhances service life capability by providing more material for erosion and the smaller open area fraction and increased thickness reduce the neutral transmission probability, thus reducing the discharge chamber neutral loss rate.

The two cylindrical apertures that a neutral particle has to pass through to escape the discharge chamber present a difficult problem to solve. Fortunately, though, Kuharski et al., modeled a two cylindrical aperture set that had a geometry that was very similar to that of the NEXT thruster (Ref. 29). They found that the angular distribution of particles exiting the accelerator grid was well modeled by assuming a single accelerator grid cylindrical aperture and 
assuming that the upstream neutral density was merely decreased by $0.93 \mathrm{x}$ due to the screen grid. This simplification was possible because of the large screen aperture diameter and low thickness relative to that of the accelerator grid. This same simplifying assumption will be exploited in this study.

\section{Far-field Equation}

Clausing was the first to develop a far-field expression for the angular distribution of particles downstream of a cylindrical aperture (Ref. 10). His equation assumes that the aperture is a point source and that the flux of particles from the walls of the aperture is linear as a function of axial thickness, which is a very accurate assumption over a range of aperture thickness-to-radius ratios (i.e., $t / R$ ) that span from 0 to about 8 (Ref. 30). The angular distribution of particles downstream of a cylindrical aperture, $T(\alpha)$, in the far-field is given by (Refs. 10 and 11):

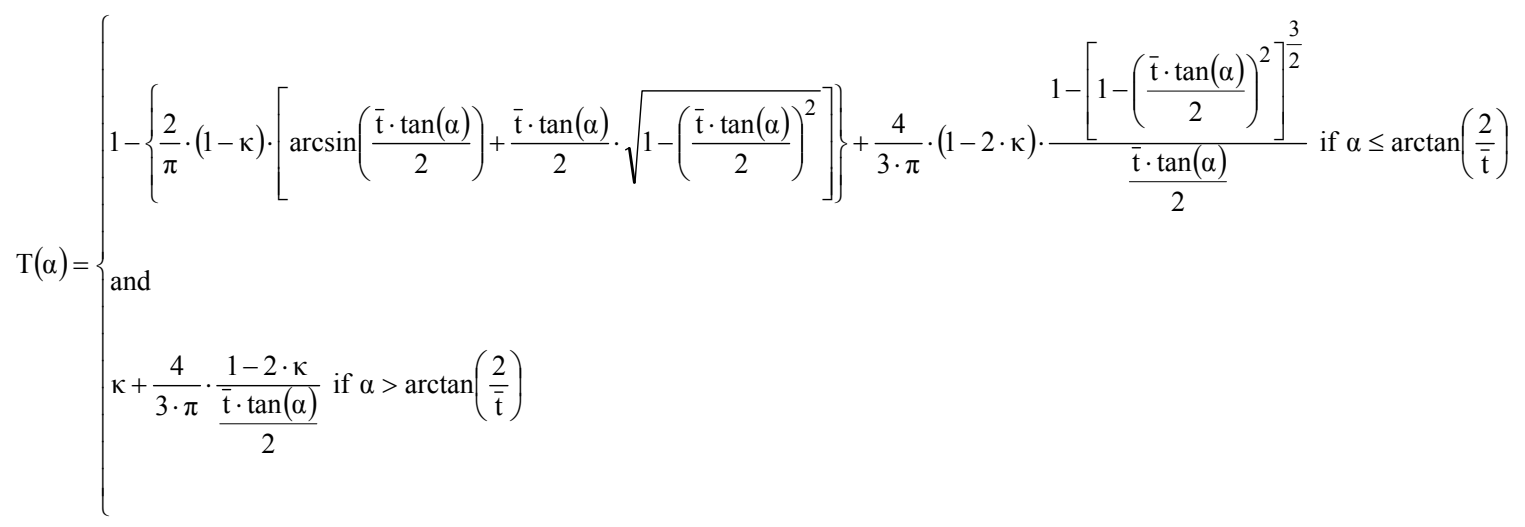

where

$$
\kappa=\frac{\sqrt{\overline{\mathrm{t}}^{2}+4}-\overline{\mathrm{t}}}{2+\frac{4}{\sqrt{\overline{\mathrm{t}}^{2}+4}}}
$$

Here, $t$ is the accelerator aperture thickness and the bar symbol denotes non-dimensionalizing by dividing the thickness with the accelerator aperture radius, $\mathrm{R}$.

Figure 3 shows the geometry for a single aperture that is treated as a point source. It can easily be shown that:

$$
\mathrm{L}=\sqrt{\mathrm{r}^{2}+\mathrm{z}^{2}}
$$

and

$$
\cos (\alpha)=\frac{\mathrm{z}}{\sqrt{\mathrm{r}^{2}+\mathrm{z}^{2}}}
$$

Equations (9) and (10), along with $\mathrm{T}(\alpha)$, can be substituted into Equation (3) to determine the downstream neutral density from a cylindrical aperture in the far-field. Note that all variables are independent of $\mathrm{dA}_{\mathrm{o}}$ because a point source is assumed, so that integral reduces to $\pi \cdot \mathrm{R}^{2}$. The resulting equation for the far-field neutral density, $\mathrm{n}_{\text {far, }}$, is:

$$
\mathrm{n}_{\text {far }}(\mathrm{r}, \mathrm{z})=\mathrm{F}_{\mathrm{scrn}} \cdot \frac{\mathrm{n}_{\mathrm{o}} \cdot \mathrm{R}^{2}}{4} \cdot \mathrm{T}\left[\arccos \left(\frac{\mathrm{z}}{\sqrt{\mathrm{r}^{2}+\mathrm{z}^{2}}}\right)\right] \cdot \frac{\mathrm{z}}{\left(\mathrm{r}^{2}+\mathrm{z}^{2}\right)^{\frac{3}{2}}}
$$




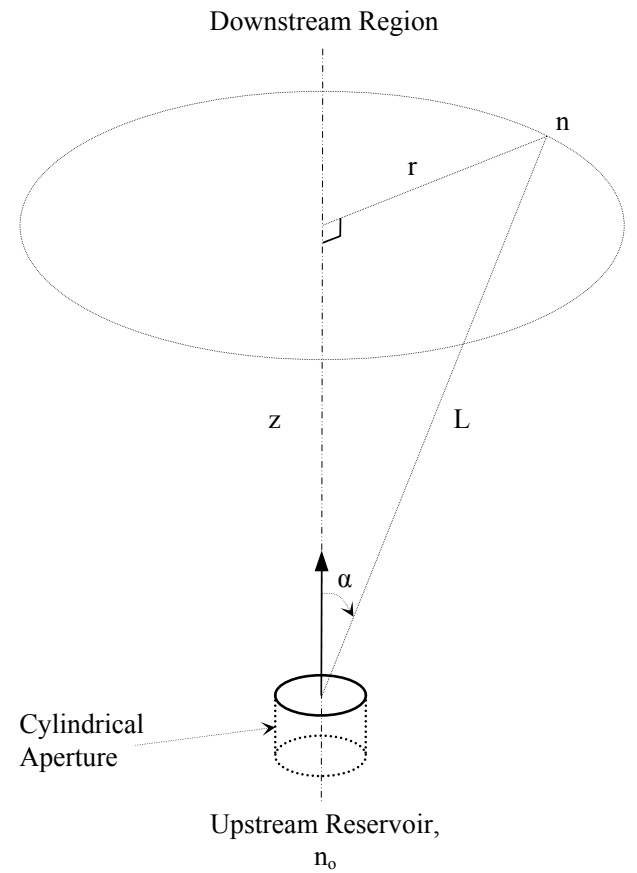

Figure 3.-Geometry for determining downstream neutral density in the far-field.

Here, $\mathrm{F}_{\text {scrn }}$ represents the correction factor to account for the upstream screen grid, which is 0.93 for the NEXT grids as discussed earlier. This correction factor can also be set equal to 1 if $\mathrm{n}_{\mathrm{o}}$ is the density upstream of accelerator grid. The far-field equation for a cylindrical aperture can be re-expressed in non-dimensional form by:

$$
\overline{\mathrm{n}}_{\mathrm{far}}(\overline{\mathrm{r}}, \overline{\mathrm{z}})=\mathrm{F}_{\mathrm{scrn}} \cdot \frac{1}{4} \cdot \mathrm{T}\left[\arccos \left(\frac{\overline{\mathrm{z}}}{\sqrt{\overline{\mathrm{r}}^{2}+\overline{\mathrm{z}}^{2}}}\right)\right] \cdot \frac{\overline{\mathrm{z}}}{\left(\overline{\mathrm{r}}^{2}+\overline{\mathrm{z}}^{2}\right)^{\frac{3}{2}}}
$$

The bar symbol above each variable denotes a non-dimensional variable. Neutral density is non-dimensionalized with the upstream neutral density, $\mathrm{n}_{\mathrm{o}}$, and $\mathrm{r}$ and $\mathrm{z}$ are non-dimensionalized with the accelerator aperture radius, $\mathrm{R}$.

\section{Near- and Far-field Equations}

Soulas developed equations for rigorously determining neutral density distribution surrounding a cylindrical aperture in the free molecular flow regime in the near- and far-fields (Ref. 30). His equations assume that the flux of particles from the walls of the aperture is linear as a function of axial thickness. Although he developed equations for the upstream, interior, and downstream regions of a cylindrical aperture, only the equations for the interior and downstream regions will be presented here. This section will only briefly review the development of these equations, although the full equation development can be found in Reference 30.

The neutral density downstream of a cylindrical aperture is made up of two components: particles that have a direct line-of-sight to a downstream location from the reservoir and from the aperture cylindrical walls. In nondimensional form, as indicated by the bar over the variable, the downstream neutral density, $\mathrm{n}_{\text {near, }}$, is given by:

$$
\begin{aligned}
\overline{\mathrm{n}}_{\text {near }}(\overline{\mathrm{r}}, \overline{\mathrm{z}})= & \frac{\mathrm{F}_{\mathrm{scrn}}}{4 \cdot \pi} \cdot\left\{\int_{\mathrm{r}_{\mathrm{oi}}}^{\mathrm{r}_{\mathrm{i}}} \frac{\overline{\mathrm{z}} \cdot \overline{\mathrm{r}}_{\mathrm{o}}}{\left[\overline{\mathrm{z}}^{2}+\overline{\mathrm{r}}^{2}+\overline{\mathrm{r}}_{\mathrm{o}}^{2}-2 \cdot \overline{\mathrm{r}} \cdot \overline{\mathrm{r}}_{\mathrm{o}} \cdot \cos (\phi)\right]^{\frac{3}{2}}} \cdot \mathrm{d} \phi \cdot \mathrm{d} \overline{\mathrm{r}}_{\mathrm{o}}\right. \\
& \left.+\int_{\overline{\mathrm{z}}_{\mathrm{wi}}}^{\overline{\mathrm{z}}_{\mathrm{wf}} \phi_{\mathrm{i}}} \frac{\phi_{\mathrm{f}}}{\left[\left(\overline{\mathrm{z}}-\overline{\mathrm{z}}_{\mathrm{w}}\right)^{2}+\overline{\mathrm{r}}^{2}+1-2 \cdot \overline{\mathrm{r}} \cdot \cos (\phi)\right]^{\frac{3}{2}}} \cdot \mathrm{d} \phi \cdot \mathrm{d} \overline{\mathrm{z}}_{\mathrm{w}}\right\}
\end{aligned}
$$


where all dimensions $\left(\mathrm{r}, \mathrm{z}, \mathrm{t}, \mathrm{r}_{\mathrm{o}}\right.$, and $\mathrm{z}_{\mathrm{w}}$ ) are non-dimensionalized with the aperture radius, $\mathrm{R}$, and the wall flux, $\Gamma_{\mathrm{w}}$, is non-dimensionalized with the reservoir flux, $\Gamma_{\mathrm{o}}$. The wall flux was assumed to be linear and its non-dimensionalized equation is given by (Ref. 30):

$$
\bar{\Gamma}_{\mathrm{w}}(\overline{\mathrm{z}})=\mathrm{a}+\mathrm{b} \cdot \overline{\mathrm{z}}
$$

where the above constants a and $\mathrm{b}$ are given by:

$$
\mathrm{a}=1-\kappa
$$

and

$$
\mathrm{b}=\frac{2 \cdot \kappa-1}{\overline{\mathrm{t}}}
$$

The first integral on the right hand side of Equation (13) represents the contribution of the reservoir to the downstream neutral density while the second integral represents the cylindrical wall's contribution. The limits of integration are a function of the downstream location (i.e., $r$ and $z$ ). The contribution of the reservoir and cylindrical wall areas depends on which portion of each area has a direct line-of-sight to the downstream location. This is illustrated in Figures 4 and 5. As shown in the figures, all reservoir and cylindrical wall areas have a direct line-ofsight to downstream locations within region I. But only a portion of the reservoir and cylindrical wall areas have a direct line-of-sight to downstream locations within regions II and III. And no reservoir particles have a direct-line of sight to downstream locations in region IV. Regions V and IV of Figures 4 and 5, respectively, lie within the walls of the cylinder. The reason for the separation of regions II and III of both areas and the further division of regions IIIa and IIIb for the reservoir was that it was mathematically necessary to correctly integrate these regions (Ref. 30).

Though complicated, the division of the downstream area into the regions illustrated in Figures 4 and 5 were used to define a set of equations with different limits of integration that can rigorously determine the neutral density downstream of a cylindrical aperture. The base equation for the downstream density, $\mathrm{n}_{\text {near }}$, in non-dimensional form is given by:

$$
\overline{\mathrm{n}}_{\text {near }}(\overline{\mathrm{r}}, \overline{\mathrm{z}})=\mathrm{F}_{\mathrm{scrn}} \cdot\left[\overline{\mathrm{n}}_{\mathrm{up}}(\overline{\mathrm{r}}, \overline{\mathrm{z}})+\overline{\mathrm{n}}_{\text {wall }}(\overline{\mathrm{r}}, \overline{\mathrm{z}})\right]
$$

where the equations for the upstream $\left(\mathrm{n}_{\mathrm{up}}\right)$ and wall $\left(\mathrm{n}_{\text {wall }}\right)$ contributions are listed in Tables 2 and 3 , respectively, with the appropriate regional border conditions to determine which region, and therefore equation, to use. As before, $\mathrm{F}_{\text {scrn }}$ represents the correction factor to account for the upstream screen grid, which is 0.93 for the NEXT thruster. Because of the linear wall flux assumption, the double integrals of Equation (13) could be reduced to single integrals in Tables 2 and 3. Note that these equations are applicable to the aperture interior and downstream regions, and that the origin for these equations is the upstream entrance to the cylindrical aperture, as shown in Figures 4 and 5 , unlike the far-field equation. The equations for the variable limits of integration used in Tables 2 and 3 are listed in Table 4. 


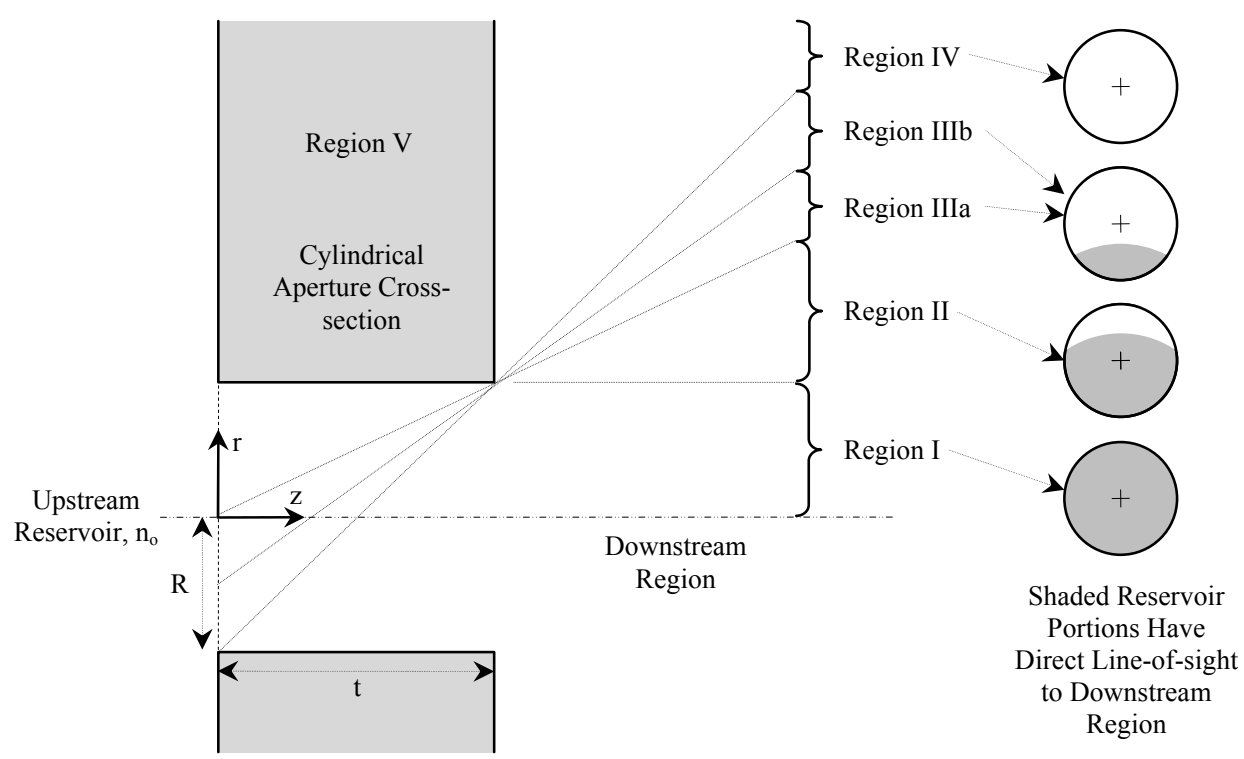

Figure 4.-Definition of downstream regions for the development of the variable limits of integration for the neutral particle flux from an upstream reservoir.

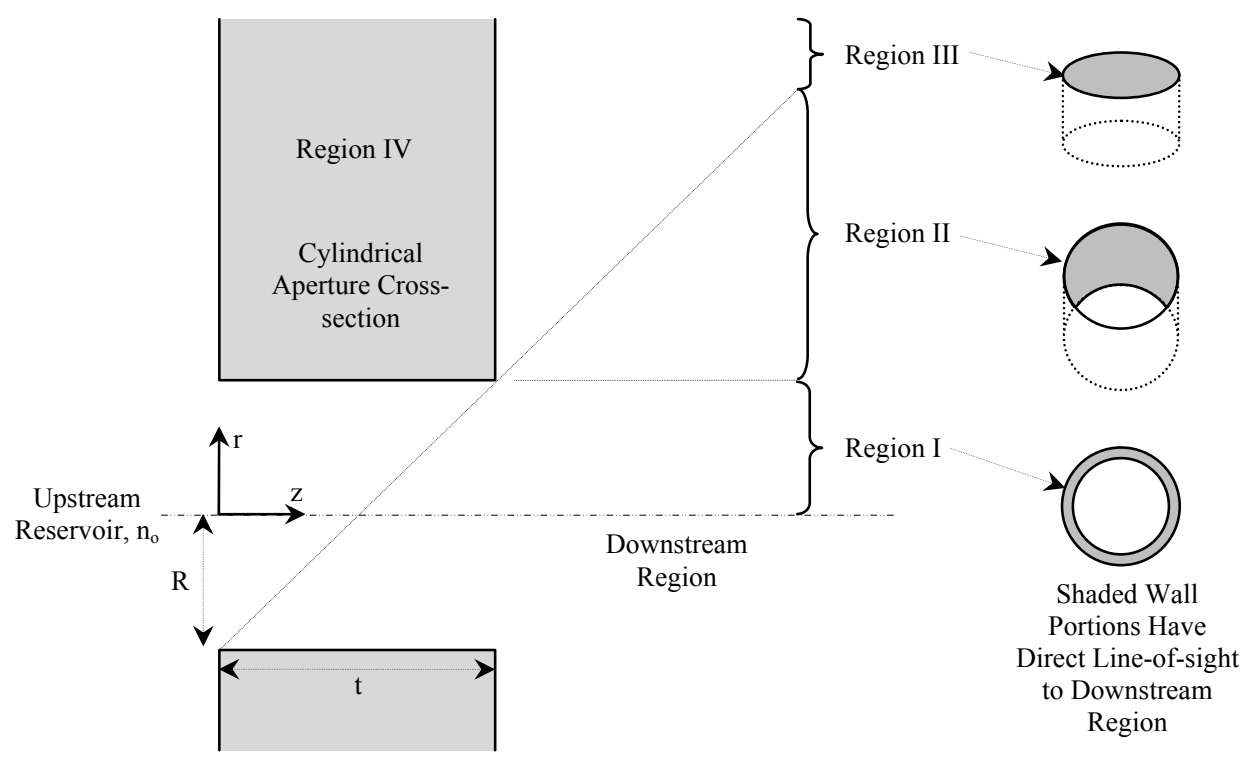

Figure 5.-Definition of downstream regions for the development of the variable limits of integration for the neutral particle flux from the cylindrical aperture walls. 


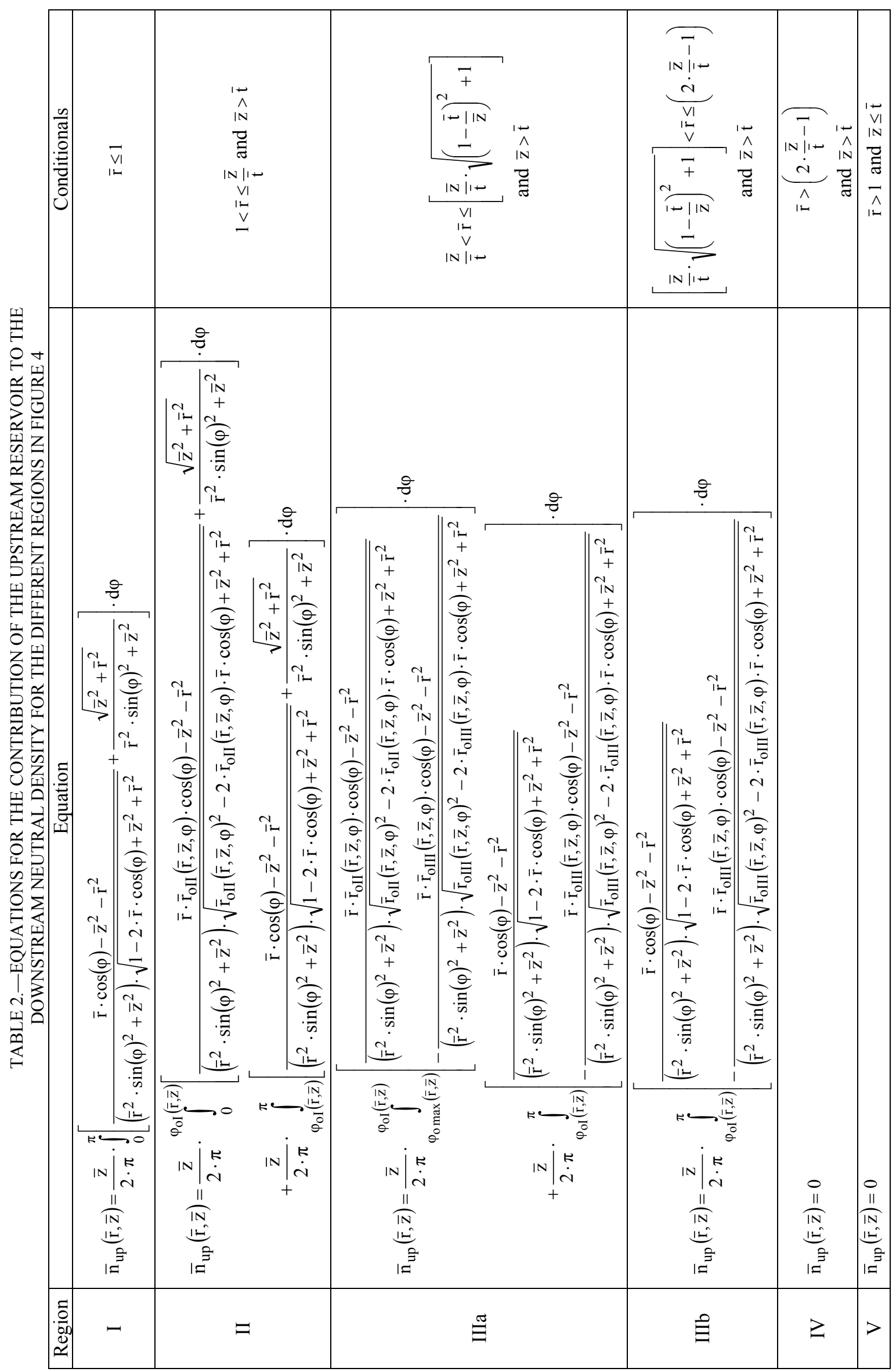




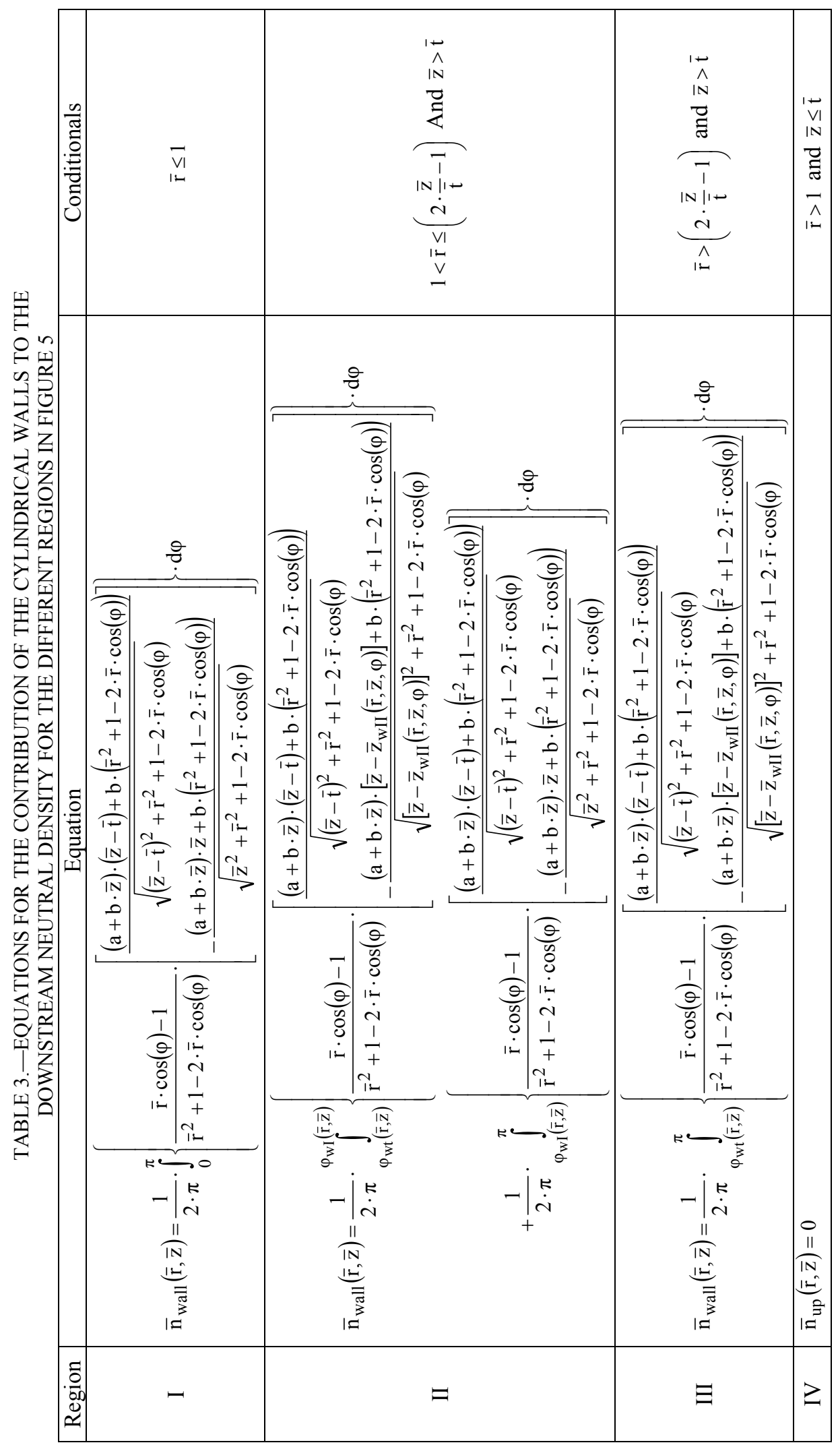


TABLE 4.-VARIABLE LIMITS OF INTEGRATION USED IN TABLES 2 AND 3

\begin{tabular}{|c|c|c|}
\hline Table use & Type & Equation \\
\hline \multirow{4}{*}{ Table 2} & \multirow{2}{*}{ Radial } & $\overline{\mathrm{r}}_{\mathrm{OII}}(\overline{\mathrm{r}}, \overline{\mathrm{z}}, \varphi)=\frac{-\frac{\overline{\mathrm{t}} \cdot \overline{\mathrm{r}}}{\overline{\mathrm{z}}} \cdot \cos (\varphi)+\sqrt{1-\left(\frac{\overline{\mathrm{t}} \cdot \overline{\mathrm{r}}}{\overline{\mathrm{z}}}\right)^{2} \cdot \sin (\varphi)^{2}}}{1-\frac{\overline{\mathrm{t}}}{\overline{\mathrm{z}}}}$ \\
\hline & & $=\frac{-\frac{\overline{\mathrm{t}} \cdot \overline{\mathrm{r}}}{\overline{\mathrm{z}}} \cdot \cos (\varphi)-\sqrt{1-\left(\frac{\overline{\mathrm{t}} \cdot \overline{\mathrm{r}}}{\overline{\mathrm{z}}}\right)^{2} \cdot \sin (\varphi)^{2}}}{1-\frac{\overline{\mathrm{t}}}{\overline{\mathrm{z}}}}$ \\
\hline & \multirow[t]{2}{*}{ Angular } & $\varphi_{\mathrm{oI}}(\overline{\mathrm{r}}, \overline{\mathrm{z}})=\arccos \left[\frac{1-\left(1-\frac{\overline{\mathrm{t}}}{\overline{\mathrm{z}}}\right)^{2}-\left(\frac{\overline{\mathrm{t}} \cdot \overline{\mathrm{r}}}{\overline{\mathrm{z}}}\right)^{2}}{2 \cdot \frac{\overline{\mathrm{t}} \cdot \overline{\mathrm{r}}}{\overline{\mathrm{z}}} \cdot\left(1-\frac{\overline{\mathrm{t}}}{\overline{\mathrm{z}}}\right)}\right]$ \\
\hline & & $\varphi_{\mathrm{omax}}(\overline{\mathrm{r}}, \overline{\mathrm{z}})=\pi-\arcsin \left(\frac{\overline{\mathrm{z}}}{\overline{\mathrm{t}} \cdot \overline{\mathrm{r}}}\right)$ \\
\hline \multirow{3}{*}{ Table 3} & Axial & $\overline{\mathrm{z}}_{\mathrm{wII}}(\overline{\mathrm{r}}, \overline{\mathrm{z}}, \varphi)=\frac{\overline{\mathrm{r}}^{2} \cdot \overline{\mathrm{t}}+\overline{\mathrm{t}}-2 \cdot \overline{\mathrm{z}}-2 \cdot \overline{\mathrm{r}} \cdot(\overline{\mathrm{t}}-\overline{\mathrm{z}}) \cdot \cos (\varphi)}{\overline{\mathrm{r}}^{2}-1}$ \\
\hline & \multirow[t]{2}{*}{ Angular } & $\varphi_{\mathrm{wI}}(\overline{\mathrm{r}}, \overline{\mathrm{z}})=\arccos \left[\frac{\overline{\mathrm{r}}^{2}+1-2 \cdot \frac{\overline{\mathrm{z}}}{\overline{\mathrm{t}}}}{2 \cdot \overline{\mathrm{r}} \cdot\left(1-\frac{\overline{\mathrm{t}}}{\overline{\mathrm{z}}}\right)}\right]$ \\
\hline & & $\varphi_{\mathrm{wt}}(\overline{\mathrm{r}}, \overline{\mathrm{z}})=\arccos \left(\frac{1}{\overline{\mathrm{r}}}\right)$ \\
\hline
\end{tabular}




\section{Convex Grid Geometric Equations and Downstream Neutral Density Equations From a Grid}

The following section will develop the geometric equations for determining downstream neutral density from a spherically-domed convex grid with a hexagonal array of apertures. The first part develops the geometric relation between the downstream neutral density and the grid surface. The second part develops aperture locations on the grid surface for a hexagonal array of holes. A cylindrical coordinate system will be used for the downstream neutral density location.

Figure 6 shows the geometric relation between the downstream neutral density located at $(\mathrm{r}, \mathrm{z})$ in a cylindrical coordinate system and a neutral emission site located on a spherically-domed convex grid. The angle between the normal of the neutral emission surface and the desired downstream neutral density location is given by $\alpha_{\text {grid }}$ and is separated by distance $\mathrm{L}_{\text {grid }}$. The axial distance, $\mathrm{z}$, is defined from the downstream center of the domed grids. The angle $\beta$ is defined as the angle from the downstream neutral density to the emission site. The variable $\gamma$ is the angle from the spherical dome center and $\gamma_{\max }$ is the angle to the edge of the perforated grid. The radius of curvature for the grid's spherical dome is given by $\mathrm{R}_{\text {grid. }}$.

To solve for the downstream neutral density, it is necessary to define $\alpha_{\text {grid }}$ and $L_{\text {grid }}$ as functions of $\gamma, \beta, \mathrm{R}_{\text {grid }}, \mathrm{r}$, and z. Using the law of cosines, it can be shown that $\alpha_{\text {grid }}$ in non-dimensional form is given by:

$\alpha_{\text {grid }}(\overline{\mathrm{r}}, \overline{\mathrm{z}}, \gamma, \beta)=\arccos \left\{\frac{\left[\frac{\overline{\mathrm{z}}+\overline{\mathrm{R}}_{\text {grid }}}{\cos (\gamma)}-\overline{\mathrm{R}}_{\text {grid }}\right]^{2}+\overline{\mathrm{L}}_{\text {grid }}^{2}-\left(\overline{\mathrm{z}}+\overline{\mathrm{R}}_{\text {grid }}\right)^{2} \cdot \tan (\gamma)^{2}-\overline{\mathrm{r}}^{2}+2 \cdot\left(\overline{\mathrm{z}}+\overline{\mathrm{R}}_{\text {grid }}\right) \cdot \tan (\gamma) \cdot \overline{\mathrm{r}} \cdot \cos (\beta)}{2 \cdot\left[\frac{\overline{\mathrm{z}}+\overline{\mathrm{R}}_{\text {grid }}}{\cos (\gamma)}-\overline{\mathrm{R}}_{\text {grid }}\right] \cdot \overline{\mathrm{L}}_{\text {grid }}}\right\}$

where all dimensions are non-dimensionalized with the accelerator aperture radius. Using the law of cosines again, the length $\mathrm{L}_{\text {grid }}$ can be shown to be given in non-dimensional form by:

$$
\overline{\mathrm{L}}_{\text {grid }}(\overline{\mathrm{r}}, \overline{\mathrm{z}}, \gamma, \beta)=\sqrt{\overline{\mathrm{r}}^{2}+\overline{\mathrm{R}}_{\text {grid }}^{2} \cdot \sin (\gamma)^{2}-2 \cdot \overline{\mathrm{r}} \cdot \overline{\mathrm{R}}_{\text {grid }} \cdot \sin (\gamma) \cdot \cos (\beta)+\left\{\overline{\mathrm{z}}+\overline{\mathrm{R}}_{\text {grid }} \cdot[1-\cos (\gamma)]^{2}\right.}
$$

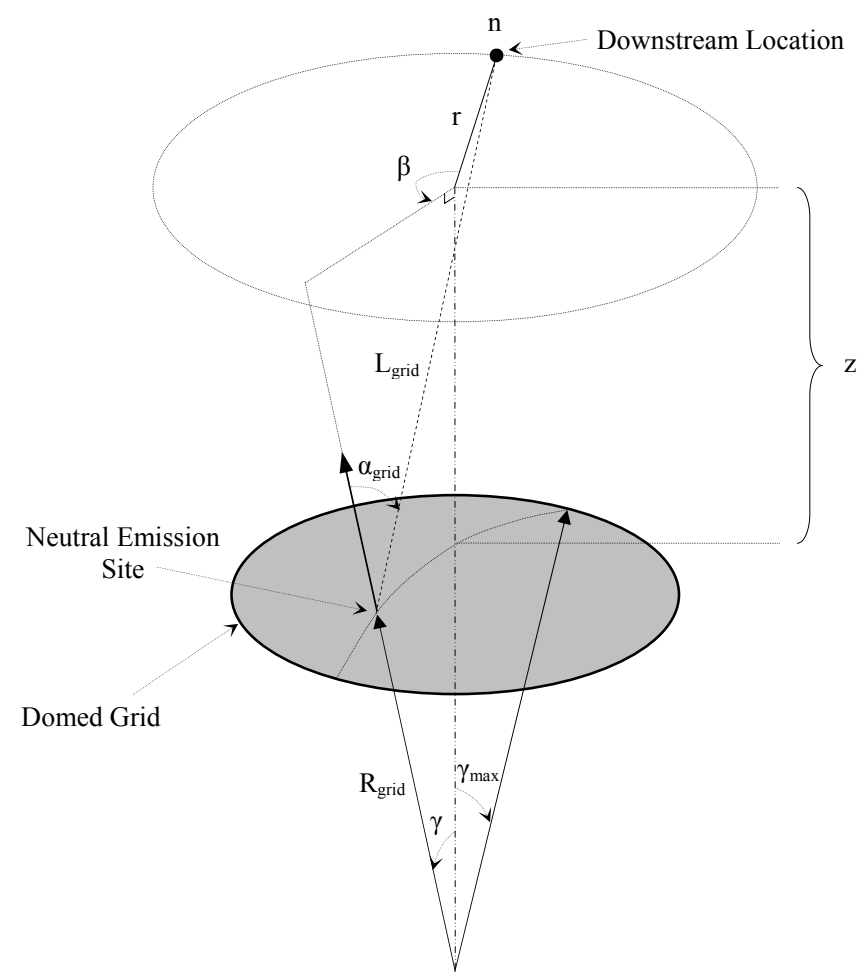

Figure 6.-The geometric relation between the downstream neutral density located at $(r, z)$ and the neutral emission site located on spherically-domed convex grid. 
For both of the aforementioned equations, all dimensions were non-dimensionalized with the accelerator aperture radius, $R$.

A typical hexagonal pattern of apertures is shown in Figure 7. It will be assumed that a center aperture exists within a spherical aperture pattern whose boundary is defined with a maximum arc angle $\gamma_{\max }$ (see Fig. 6). All other aperture locations can be determined as a function of $\gamma$ and $\beta$ in spherical coordinates relative to this center aperture by adding apertures along the sides of successively larger hexagons centered about this center aperture. Such an approach simplifies calculations because of symmetry because the hexagonal pattern can be divided into 6 sides.

For this study, $\gamma$ and $\beta$ were defined as functions of three integer values and the aperture center-to-center spacing, $1_{c c}$, explained below and illustrated in Figure 7. Note that for a spherically-domed grid, $1_{c c}$ is an arc length. Along a given hexagon's side, $\mathrm{k}$, and $\mathrm{p} \cdot \mathrm{l}_{\mathrm{cc}}$ distance along a major radius (e.g., along $\beta=0$ ), where $\mathrm{p}$ is the number of apertures, aperture centerlines are located $\mathrm{m} \cdot \mathrm{l}_{\mathrm{cc}}$ away from the major radius. It can be shown that $\gamma$ and $\beta$ as functions of $\mathrm{k}, \mathrm{m}$, and $\mathrm{p}$ are given by:

$$
\gamma_{\mathrm{m}, \mathrm{p}}=\frac{\frac{\mathrm{p} \cdot 1_{\mathrm{cc}}}{\mathrm{R}_{\text {grid }}} \cdot \cos \left(\frac{\pi}{6}\right)}{\cos \left\{\arctan \left[\frac{\frac{\mathrm{p}}{2}-\mathrm{m}}{\mathrm{p} \cdot \cos \left(\frac{\pi}{6}\right)}\right]\right\}}
$$

and

$$
\beta_{\mathrm{k}, \mathrm{m}, \mathrm{p}}=\frac{\pi}{6}-\arctan \left[\frac{\frac{\mathrm{p}}{2}-\mathrm{m}}{\mathrm{p} \cdot \cos \left(\frac{\pi}{6}\right)}\right]+(\mathrm{k}-1) \cdot \frac{\pi}{3}
$$

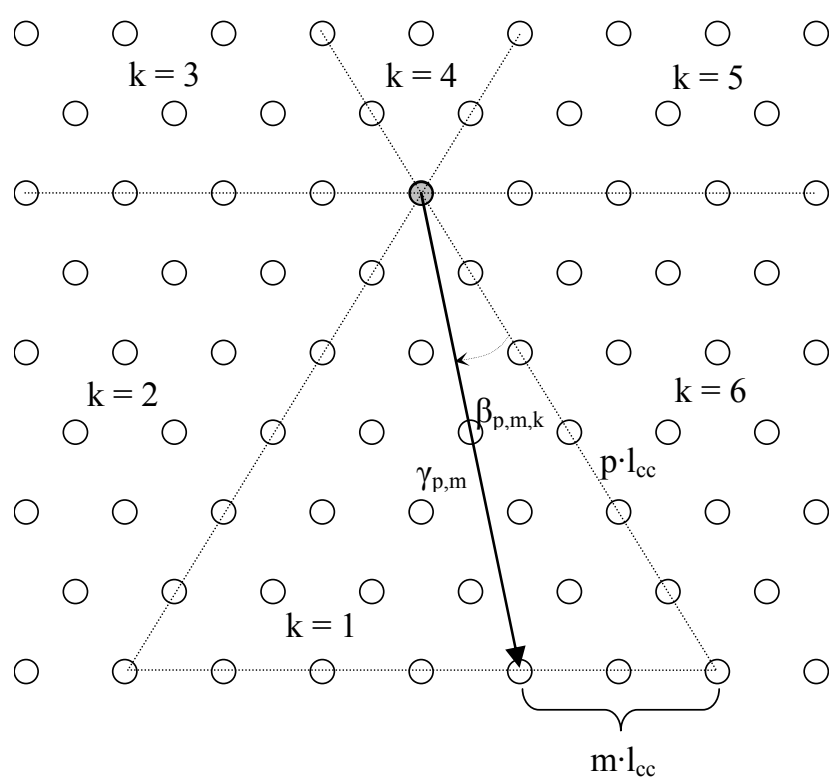

Figure 7.-Typical hexagonal aperture pattern for a sphericallydomed convex grid. The center aperture is depicted in gray. 
To determine the $\gamma$ and $\beta$ locations of every aperture along a hexagon for a given $p$ from the center aperture, $\gamma$ and $\beta$ are calculated from $m=0$ to $p-1$, and these calculations for $\beta$ are repeated from $k=1$ to 6 to account for all 6 sides of the hexagon (because of symmetry, $\gamma$ is independent of $\mathrm{k}$ ). This process of determining aperture locations in $\gamma$ and $\beta$ coordinates as functions of $\mathrm{k}, \mathrm{m}$, and $\mathrm{p}$ by building successively larger hexagonal patterns of apertures is continued until $\mathrm{p} \cdot \mathrm{l}_{\mathrm{cc}} / \mathrm{R}_{\text {grid }} \leq \gamma_{\max }$. Beyond this, aperture radial locations must be checked against the aperture pattern boundary to ensure that apertures at $\gamma_{\mathrm{m}, \mathrm{p}}>\gamma_{\max }$ are excluded because they lie beyond this boundary. This process is continued until $p$ reaches a maximum value, $p_{\max }$, which is defined as:

$$
\mathrm{p}_{\max }=\left\lceil\frac{\gamma_{\max }}{\frac{\mathrm{l}_{\mathrm{cc}}}{\mathrm{R}_{\text {grid }}} \cdot \cos \left(\frac{\pi}{6}\right)}\right\rceil
$$

where the brackets about the right hand side of the equation denote the ceiling function.

With the locations of each individual aperture, $\alpha_{\text {grid }}$, and $\mathrm{L}_{\text {grid }}$ defined in the above equations, the downstream neutral density from a convex spherical dome can now be determined. The far-field neutral density can be solved as was done for Equation (12). It can be shown that with the far-field angular distribution function, the neutral density downstream of a convex grid, $\mathrm{n}_{\text {far-gridsum, }}$ is given in non-dimensional form by:

$$
\begin{aligned}
\overline{\mathrm{n}}_{\text {far }- \text { gridsum }}(\overline{\mathrm{r}}, \overline{\mathrm{z}})= & \frac{\mathrm{F}_{\text {scrn }} \cdot \mathrm{T}\left[\alpha_{\text {grid }}(\overline{\mathrm{r}}, \overline{\mathrm{z}}, \gamma=0, \beta=0)\right]}{4} \cdot \frac{\cos \left[\alpha_{\text {grid }}(\overline{\mathrm{r}}, \overline{\mathrm{z}}, \gamma=0, \beta=0)\right]}{\overline{\mathrm{L}}_{\text {grid }}^{2}(\overline{\mathrm{r}}, \overline{\mathrm{z}}, \gamma=0, \beta=0)} \\
& +\sum_{\mathrm{p}=1}^{\mathrm{p}_{\max }} \sum_{\mathrm{k}=1}^{6} \sum_{\mathrm{m}=0}^{\mathrm{p}-1}\left\{\begin{array}{l}
\frac{\mathrm{F}_{\text {scrn }} \cdot \mathrm{T}\left[\alpha_{\text {grid }}\left(\overline{\mathrm{r}}, \overline{\mathrm{z}}, \gamma_{\mathrm{m}, \mathrm{p}}, \beta_{\mathrm{k}, \mathrm{m}, \mathrm{p}}\right)\right]}{4} \cdot \frac{\cos \left[\alpha_{\text {grid }}\left(\overline{\mathrm{r}}, \overline{\mathrm{z}}, \gamma_{\mathrm{m}, \mathrm{p}}, \beta_{\mathrm{k}, \mathrm{m}, \mathrm{p}}\right)\right]}{\overline{\mathrm{L}}_{\text {grid }}^{2}\left(\overline{\mathrm{r}}, \overline{\mathrm{z}}, \gamma_{\mathrm{m}, \mathrm{p}}, \beta_{\mathrm{k}, \mathrm{m}, \mathrm{p}}\right)} \text { if } \gamma_{\mathrm{m}, \mathrm{p}} \leq \gamma_{\text {max }} \\
0 \text { if } \gamma_{\mathrm{m}, \mathrm{p}}>\gamma_{\max }
\end{array}\right.
\end{aligned}
$$

The first term on the right hand side of the equation above is the center aperture's contribution to the downstream neutral density while the second term includes all other apertures. The second term on the right hand side also includes conditional statements to ensure that apertures located beyond the aperture pattern boundary are not included in the calculation. The variables $\alpha_{\text {grid }}, \mathrm{L}_{\text {grid }}, \gamma, \beta$, and $\mathrm{p}_{\max }$ are defined in Equations (18) to (22), respectively. This equation can be generalized further by accounting for variations in the upstream neutral density within the discharge chamber as a function of $\gamma$ and $\beta$ (i.e., across the grids). It is assumed that upstream neutral density distribution can be described by:

$$
\mathrm{n}_{\mathrm{o}}(\gamma, \beta)=\mathrm{n}_{\mathrm{o}} \cdot \mathrm{D}(\gamma, \beta)
$$

where $\mathrm{D}$ is a distribution function and $\mathrm{n}_{\mathrm{o}}$ is now an average upstream neutral density. So, Equation (23) can be generalized with Equation (24) to yield: 


$$
\begin{aligned}
& \overline{\mathrm{n}}_{\text {far-gridsum }}(\overline{\mathrm{r}}, \overline{\mathrm{z}})=\frac{\mathrm{F}_{\text {scrn }} \cdot \mathrm{T}\left[\alpha_{\text {grid }}(\overline{\mathrm{r}}, \overline{\mathrm{z}}, \gamma=0, \beta=0)\right] \cdot \mathrm{D}(\gamma=0, \beta=0)}{4} \cdot \frac{\cos \left[\alpha_{\text {grid }}(\overline{\mathrm{r}}, \overline{\mathrm{z}}, \gamma=0, \beta=0)\right]}{\overline{\mathrm{L}}_{\text {grid }}^{2}(\overline{\mathrm{r}}, \overline{\mathrm{z}}, \gamma=0, \beta=0)} \\
& +\sum_{\mathrm{p}=1}^{\mathrm{p}_{\text {max }}} \sum_{\mathrm{k}=1}^{6} \sum_{\mathrm{m}=0}^{\mathrm{p}-1}\left\{\begin{array}{l}
\frac{\mathrm{F}_{\text {scrn }} \cdot \mathrm{T}\left[\alpha_{\text {grid }}\left(\overline{\mathrm{r}}, \overline{\mathrm{z}}, \gamma_{\mathrm{m}, \mathrm{p}}, \beta_{\mathrm{k}, \mathrm{m}, \mathrm{p}}\right)\right] \cdot \mathrm{D}\left(\gamma_{\mathrm{m}, \mathrm{p}}, \beta_{\mathrm{k}, \mathrm{m}, \mathrm{p}}\right)}{4} \cdot \frac{\cos \left[\alpha_{\text {grid }}\left(\overline{\mathrm{r}}, \overline{\mathrm{z}}, \gamma_{\mathrm{m}, \mathrm{p}}, \beta_{\mathrm{k}, \mathrm{m}, \mathrm{p}}\right)\right]}{\overline{\mathrm{L}}_{\text {grid }}^{2}\left(\overline{\mathrm{r}}, \overline{\mathrm{z}}, \gamma_{\mathrm{m}, \mathrm{p}}, \beta_{\mathrm{k}, \mathrm{m}, \mathrm{p}}\right)} \text { if } \gamma_{\mathrm{m}, \mathrm{p}} \leq \gamma_{\max } \\
\text { and } \\
0 \text { if } \gamma_{\mathrm{m}, \mathrm{p}}>\gamma_{\max }
\end{array}\right.
\end{aligned}
$$

Equations (23) and (25) are non-dimensionalized with the average discharge chamber upstream neutral density, $\mathrm{n}_{\mathrm{o}}$.

Further away from the grid, it will be shown that it is reasonable to neglect individual apertures and treat the entire grid surface as a neutral-emitting surface. The generalized solution can be solved by starting with Equation (3) and noting that:

$$
\mathrm{dA}_{\mathrm{o}}=\mathrm{R}_{\text {grid }}^{2} \cdot \sin (\gamma) \cdot \mathrm{d} \gamma \cdot \mathrm{d} \beta
$$

Equations (24) and (26) can be substituted into Equation (3) to yield the neutral density downstream of a convex grid, $\mathrm{n}_{\text {far-gridint }}$ in non-dimensional form:

$$
\overline{\mathrm{n}}_{\text {far-grid int }}(\overline{\mathrm{r}}, \overline{\mathrm{z}})=\frac{\overline{\mathrm{R}}_{\text {grid }}^{2} \cdot \mathrm{F}_{\mathrm{oa}} \cdot \mathrm{F}_{\text {scrn }}}{4 \cdot \pi} \cdot \int_{0}^{2 \cdot \pi} \int_{0}^{\gamma_{\max }} \mathrm{D}(\gamma, \beta) \cdot \mathrm{T}\left[\alpha_{\text {grid }}(\overline{\mathrm{r}}, \overline{\mathrm{z}}, \gamma, \beta)\right] \cdot \frac{\cos \left[\alpha_{\text {grid }}(\overline{\mathrm{r}}, \overline{\mathrm{z}}, \gamma, \beta)\right]}{\overline{\mathrm{L}}_{\text {grid }}^{2}(\overline{\mathrm{r}}, \overline{\mathrm{z}}, \gamma, \beta)} \cdot \sin (\gamma) \cdot \mathrm{d} \gamma \cdot \mathrm{d} \beta
$$

Here, the equation is non-dimensionalized with the average discharge chamber upstream neutral density $\left(\mathrm{n}_{\mathrm{o}}\right), \alpha_{\text {grid, }}$, $\mathrm{L}_{\text {grid, }}$, and $\mathrm{T}$ are given by Equations (18), (19), and (7), respectively, and $\mathrm{F}_{\mathrm{oa}}$ is the accelerator grid open area fraction that is given by:

$$
\mathrm{F}_{\mathrm{oa}}=\frac{2 \cdot \pi \cdot \mathrm{R}^{2}}{\sqrt{3} \cdot 1_{\mathrm{cc}}^{2}}
$$

Equation (28) is only valid as long as $1_{c c}$ is very small in comparison to $R_{\text {grid. }}$.

Equation (17), which is valid in the near- and far-fields, can also be applied to the grids. This is done by transforming $\mathrm{r}$ and $\mathrm{z}$ of the aperture coordinate system in Equation (17) to the grid coordinate system (i.e., by defining $r$ and $z$ in the aperture coordinate system as functions of $\gamma, \beta, \mathrm{R}_{\text {grid }}, r$, and $\mathrm{z}$ in the grid coordinate system of Figure 6). The contribution of all apertures can then be summed in a manner similar to Equation (25). It can be shown that the result in non-dimensional form is:

$$
\begin{aligned}
\overline{\mathrm{n}}_{\text {near-gridsum }}(\overline{\mathrm{r}}, \overline{\mathrm{z}})= & \overline{\mathrm{n}}_{\text {near }}\left[\overline{\mathrm{r}}_{\text {near }}(\overline{\mathrm{r}}, \overline{\mathrm{z}}, \gamma=0, \beta=0), \overline{\mathrm{z}}_{\text {near }}(\overline{\mathrm{r}}, \overline{\mathrm{z}}, \gamma=0, \beta=0)\right] \cdot \mathrm{D}(\gamma=0, \beta=0) \\
& +\sum_{\mathrm{p}=1}^{\mathrm{p}_{\max }} \sum_{\mathrm{k}=1}^{6} \sum_{\mathrm{m}=0}^{\mathrm{p}-1}\left\{\begin{array}{l}
\overline{\mathrm{n}}_{\text {near }}\left[\overline{\mathrm{r}}_{\text {near }}\left(\overline{\mathrm{r}}, \overline{\mathrm{z}}, \gamma_{\mathrm{m}, \mathrm{p}}, \beta_{\mathrm{k}, \mathrm{m}, \mathrm{p}}\right), \overline{\mathrm{z}}_{\text {near }}\left(\overline{\mathrm{r}}, \overline{\mathrm{z}}, \gamma_{\mathrm{m}, \mathrm{p}}, \beta_{\mathrm{k}, \mathrm{m}, \mathrm{p}}\right)\right] \cdot \mathrm{D}\left(\gamma_{\mathrm{m}, \mathrm{p}}, \beta_{\mathrm{k}, \mathrm{m}, \mathrm{p}}\right) \text { if } \gamma_{\mathrm{m}, \mathrm{p}} \leq \gamma_{\max } \\
\text { and } \\
0 \text { if } \gamma_{\mathrm{m}, \mathrm{p}}>\gamma_{\max }
\end{array}\right.
\end{aligned}
$$


where $\mathrm{n}_{\text {near }}, \gamma, \beta$, and $\mathrm{p}_{\max }$, are given by Equations (17), (20), (21), and (22), respectively, $\mathrm{D}$ is given by Equation (24), and

$$
\overline{\mathrm{r}}_{\text {near }}=\overline{\mathrm{L}}_{\text {grid }}(\overline{\mathrm{r}}, \overline{\mathrm{z}}, \gamma, \beta) \cdot \sin \left[\alpha_{\text {grid }}(\overline{\mathrm{r}}, \overline{\mathrm{z}}, \gamma, \beta)\right]
$$

and

$$
\overline{\mathrm{z}}_{\text {near }}=\overline{\mathrm{L}}_{\text {grid }}(\overline{\mathrm{r}}, \overline{\mathrm{z}}, \gamma, \beta) \cdot \cos \left[\alpha_{\text {grid }}(\overline{\mathrm{r}}, \overline{\mathrm{z}}, \gamma, \beta)\right]+\overline{\mathrm{t}}
$$

The variables $\alpha_{\text {grid }}$ and $\mathrm{L}_{\text {grid }}$ are given by Equations (18) and (19), respectively. Equations (29) to (31) are non-dimensionalized with the average discharge chamber neutral density, $\mathrm{n}_{\mathrm{o}}$.

\section{Downstream Neutral Density Equation for a Neutralizer}

For the neutralizer, the gas upstream of the cathode orifice is collisional, so that the aforementioned equations for the "beaming" effects of cylindrical apertures in the free molecular flow regime do not apply. Although one option is to treat the gas exiting the cathode as a simple choked flow through an orifice, the discharge between the neutralizer cathode and its keeper and the ion beam will undoubtedly affect the angular distribution of neutral gas in the downstream region. Unfortunately, accurately modeling such effects is beyond the scope of this study. However, because the neutralizer discharge would likely randomize the spatial velocity distribution of the neutral gas particles, this study will assume that the neutrals exit the neutralizer keeper orifice diffusely.

Figure 8 shows the geometric relation between the downstream neutral density located at $(r, z)$ in a cylindrical coordinate system and the neutralizer keeper orifice. The angle between the normal of the neutralizer keeper orifice emission area and the downstream neutral density is given by $\alpha_{\text {neut }}$ and is separated by distance $\mathrm{L}_{\text {neut }}$. The axial and radial distances, $\mathrm{z}$ and $\mathrm{r}$, are referenced to the downstream center of the domed grids, as was done for the grids in Figure 6 . The angle $\beta$ is defined as being $0^{\circ}$ to the neutralizer centerline. The variables $z_{\text {noff }}$ and $r_{\text {noff }}$ are the axial and radial offsets, respectively, of the neutralizer keeper orifice emission area center from the downstream center of the domed grid. The variables $r_{n o}$ and $\theta$ are the radius and azimuthal angle for the neutralizer keeper orifice area, respectively.

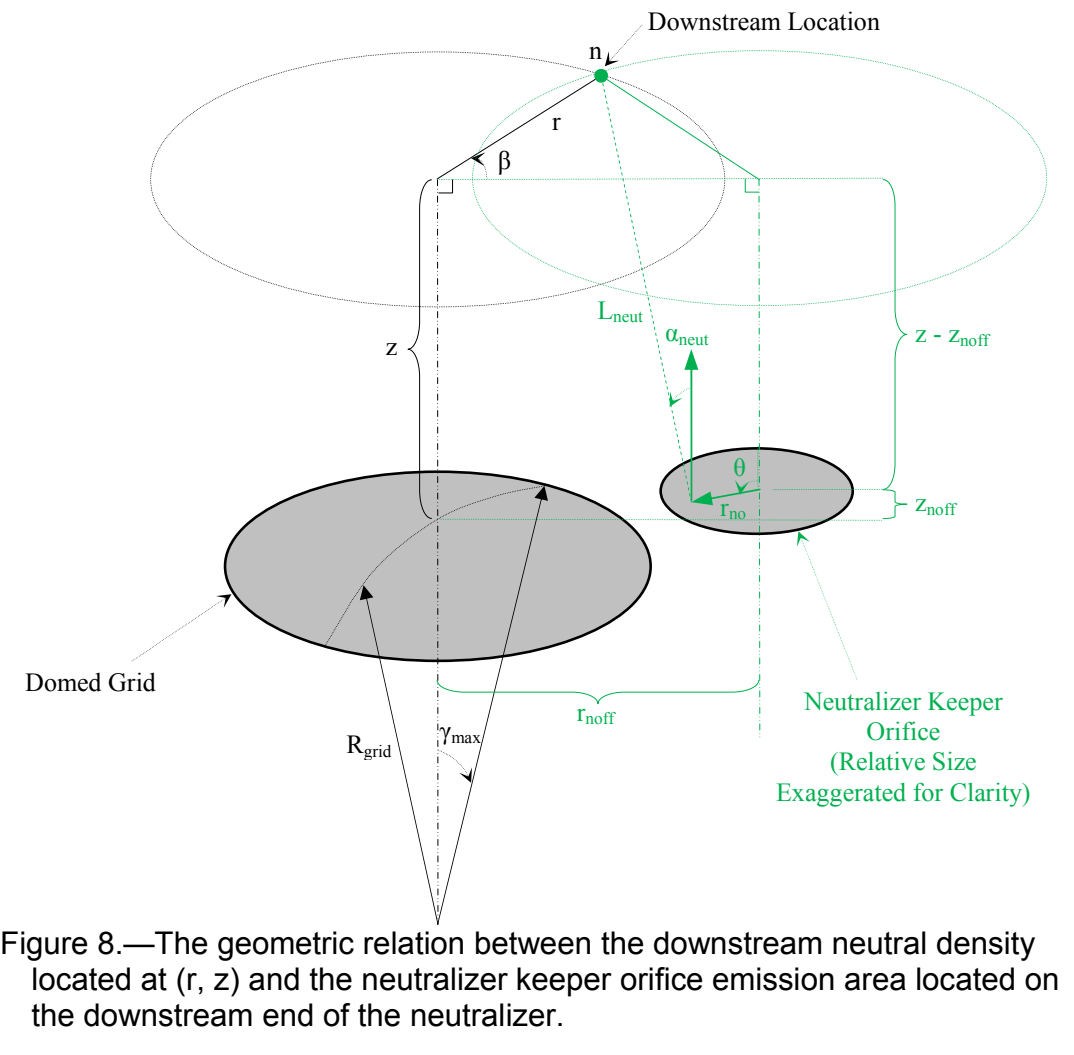


To solve for the downstream neutral density, it is necessary to define $\alpha_{\text {neut }}$ and $\mathrm{L}_{\text {neut }}$ as functions of $\mathrm{r}, \mathrm{z}, \beta, \mathrm{r}_{\mathrm{n}}$, and $\theta$. It can be shown that $\alpha_{\text {neut }}$ is given in non-dimensional form by

$$
\alpha_{\text {neut }}\left(\overline{\mathrm{r}}, \overline{\mathrm{z}}, \beta, \overline{\mathrm{r}}_{\text {no }}, \theta\right)=\arccos \left\{\frac{\overline{\mathrm{z}}-\overline{\mathrm{z}}_{\text {noff }}}{\overline{\mathrm{L}}_{\text {neut }}\left(\overline{\mathrm{r}}, \overline{\mathrm{z}}, \beta, \overline{\mathrm{r}}_{\text {no }}, \theta\right)}\right\}
$$

The length $\mathrm{L}_{\text {neut }}$ can be shown to be given in non-dimensional form by:

$$
\begin{aligned}
& \overline{\mathrm{L}}_{\text {neut }}\left(\overline{\mathrm{r}}, \overline{\mathrm{z}}, \beta, \overline{\mathrm{r}}_{\text {no }}, \theta\right)= \\
& \quad \sqrt{\overline{\mathrm{r}}_{\text {noff }}^{2}+\overline{\mathrm{r}}^{2}-2 \cdot \overline{\mathrm{r}}_{\text {noff }} \cdot \overline{\mathrm{r}} \cdot \cos (\beta)+\overline{\mathrm{r}}_{\text {no }}^{2}-2 \cdot \sqrt{\overline{\mathrm{r}}_{\text {noff }}^{2}+\overline{\mathrm{r}}^{2}-2 \cdot \overline{\mathrm{r}}_{\text {noff }} \cdot \overline{\mathrm{r}} \cdot \cos (\beta)} \cdot \overline{\mathrm{r}}_{\text {no }} \cdot \cos (\theta)+\left(\overline{\mathrm{z}}-\overline{\mathrm{z}}_{\text {noff }}\right)^{2}}
\end{aligned}
$$

For both of the aforementioned equations, all dimensions were non-dimensionalized with the accelerator aperture radius, $\mathrm{R}$.

With $\alpha_{\text {neut }}$ and $\mathrm{L}_{\text {neut }}$ defined in the above equations, the downstream neutral density from the neutralizer can now be determined. The neutral density within the keeper orifice can be solved as was done for Equation (11) and noting that:

$$
\dot{\mathrm{m}}_{\text {neut }}=\frac{\mathrm{n}_{\mathrm{o}, \text { neut }} \cdot \mathrm{c}}{4} \cdot \mathrm{m}_{\mathrm{n}} \cdot \pi \cdot \mathrm{R}_{\mathrm{no}}^{2}
$$

where $\dot{\mathrm{m}}_{\text {neut }}$ is the neutralizer mass flow rate, $\mathrm{n}_{\mathrm{o} \text {,neut }}$ is a reservoir neutral density, $\mathrm{R}_{\mathrm{no}}$ is the neutralizer keeper orifice radius, and $m_{n}$ is the molecular mass of the neutral gas. It can be shown that the neutral density downstream of a neutralizer, $\mathrm{n}_{\text {neut }}$, is given in non-dimensional form by:

$$
\overline{\mathrm{n}}_{\text {neut }}(\overline{\mathrm{r}}, \overline{\mathrm{z}}, \beta)=\left\{\begin{array}{l}
\frac{\dot{\mathrm{m}}_{\text {neut }}}{\mathrm{m}_{\mathrm{n}} \cdot \mathrm{c} \cdot \pi^{2} \cdot \mathrm{R}_{\mathrm{no}}^{2} \cdot \mathrm{n}_{\mathrm{o}}} \cdot \int_{0}^{2 \cdot \pi} \int_{0}^{\overline{\mathrm{R}}_{\text {no }}} \frac{\cos \left[\alpha_{\text {neut }}\left(\overline{\mathrm{r}}, \overline{\mathrm{z}}, \beta, \overline{\mathrm{r}}_{\mathrm{no}}, \theta\right)\right]}{\overline{\mathrm{L}}_{\text {neut }}^{2}\left(\overline{\mathrm{r}}, \overline{\mathrm{z}}, \beta, \overline{\mathrm{r}}_{\mathrm{no}}, \theta\right)} \cdot \overline{\mathrm{r}}_{\text {no }} \cdot \mathrm{dr} \overline{\mathrm{r}}_{\mathrm{no}} \cdot \mathrm{d} \theta \text { if } \overline{\mathrm{z}} \geq \overline{\mathrm{z}}_{\text {noff }} \\
\text { and } \\
0 \text { if } \overline{\mathrm{z}}<\overline{\mathrm{z}}_{\text {noff }}
\end{array}\right.
$$

The variables $\alpha_{\text {neut }}$ and $\mathrm{L}_{\text {neut }}$ are given by Equations (32) and (33), respectively. The neutralizer neutral density was non-dimensionalized with average discharge chamber upstream neutral density, $\mathrm{n}_{\mathrm{o}}$. The conditionals ensure that there is no contribution from the neutralizer for axial locations less than $z_{\text {noff }}$ because neutralizer neutrals have no direct line-of-sight to those axial locations. Note that the neutralizer downstream density is a function of $\beta$, unlike the equations for the downstream neutral density from the grids, which are nearly axisymmetric so that $\beta$ can be ignored.

\section{E. Background Vacuum Facility Neutrals}

The background neutrals within the vacuum facility are those particles emitted from the thruster (i.e., neutrals, beam ions, charge-exchange ions, and neutralizer ions) that have been reflected from a facility surface. It is assumed in this study that free molecular flow conditions exist within the facility and that facility neutral particle velocities are isotropic. And although the vacuum facility particles will typically have a lower temperature than those particles emanating from the thruster (see, for example, Ref. 36 for NEXT ion thruster temperatures), it will be assumed that vacuum facility neutrals reflected from thruster surfaces will still have vacuum facility wall temperatures and are reflected diffusely. Finally, it is assumed that the neutral density throughout the vacuum facility is uniform, which is a reasonable assumption for thruster operation in large vacuum facilities. 
Because of the aforementioned assumptions, the inclusion of vacuum facility neutrals is straightforward. The background facility neutral density need only be added to the neutral densities from the neutrals escaping from the grids and neutralizer. The background facility neutral density, $\mathrm{n}_{\text {tank }}$, as a function of pressure and wall temperature is given in non-dimensional form by:

$$
\overline{\mathrm{n}}_{\text {tank }}=\frac{\mathrm{n}_{\text {tank }}}{\mathrm{n}_{\mathrm{o}}}=\frac{\mathrm{p}_{\text {tank }}}{\mathrm{k}_{\mathrm{B}} \cdot \mathrm{T}_{\text {tank }} \cdot \mathrm{n}_{\mathrm{o}}}
$$

Here, $\mathrm{p}_{\text {tank }}$ and $\mathrm{T}_{\text {tank }}$ are the vacuum facility background pressure and wall temperature and $\mathrm{k}_{\mathrm{B}}$ is the Boltzmann constant. The facility neutral density was non-dimensionalized with average discharge chamber upstream neutral density, $\mathrm{n}_{\mathrm{o}}$.

\section{F. Total Neutral Density Downstream of an Ion Thruster}

As discussed earlier, the downstream neutral density contributions of each neutral source can be added together because ion thrusters typically operate within the free molecular regime downstream of the thruster. So, the total neutral density downstream of an ion thruster, $\mathrm{n}_{\mathrm{tot}}$, is given in non-dimensional form by:

$$
\overline{\mathrm{n}}_{\text {tot }}(\overline{\mathrm{r}}, \overline{\mathrm{z}}, \beta)=\overline{\mathrm{n}}_{\text {grid }}(\overline{\mathrm{r}}, \overline{\mathrm{z}})+\overline{\mathrm{n}}_{\text {neut }}(\overline{\mathrm{r}}, \overline{\mathrm{z}}, \beta)+\overline{\mathrm{n}}_{\text {tan } \mathrm{k}}
$$

Here, $\mathrm{n}_{\text {grid }}$ is the discharge chamber contribution given by either Equations (25), (27), or (29); $\mathrm{n}_{\text {neut }}$ is the neutralizer contribution given by Equation (35); and $\mathrm{n}_{\text {tank }}$ is the vacuum facility contribution given by Equation (36). Note that only the neutralizer density is a function of $\beta$, which is $0^{\circ}$ in the direction of the neutralizer. Although the hexagonal pattern of the apertures within the grid leads to a dependence on $\beta$ for Equations (25) and (29), it is neglected in this equation because the pattern is nearly axisymmetric for the typically small accelerator grid apertures.

All of the terms within Equation (37) are non-dimensionalized with the average discharge chamber neutral density, $\mathrm{n}_{0}$. It can be shown that this neutral density is given by:

$$
\mathrm{n}_{\mathrm{o}}=\frac{\dot{\mathrm{m}}_{\mathrm{d}}-\mathrm{J}_{\mathrm{b}} \cdot \frac{\mathrm{m}_{\mathrm{n}}}{\mathrm{e}} \cdot \frac{1+\frac{1}{2} \cdot \frac{\mathrm{J}^{++}}{\mathrm{J}^{+}}}{1+\frac{\mathrm{J}^{++}}{\mathrm{J}^{+}}}}{\sqrt{2 \cdot \pi \cdot \mathrm{k}_{\mathrm{B}} \cdot \mathrm{T}_{\mathrm{o}} \cdot \mathrm{m}_{\mathrm{n}}} \cdot \mathrm{R}_{\text {grid }}^{2} \cdot\left[1-\cos \left(\gamma_{\max }\right)\right] \cdot \mathrm{F}_{\mathrm{oa}} \cdot \mathrm{K}_{\mathrm{c}} \cdot \mathrm{F}_{\mathrm{scrn}}}
$$

Here, $\dot{\mathrm{m}}_{\mathrm{d}}$ is the total discharge flow rate, $\mathrm{J}_{\mathrm{b}}$ is the beam current, e is the charge of an electron (i.e., $1.602 \times 10^{-19} \mathrm{C}$ ), $\mathrm{J}^{++} / \mathrm{J}^{+}$is the discharge chamber total doubly-to-singly-charged ion current ratio, and $\mathrm{T}_{\mathrm{o}}$ is the discharge chamber neutral gas temperature. The variable $\mathrm{K}_{\mathrm{c}}$ is the transmission probability of neutrals through an accelerator grid aperture and is given by (Ref. 11):

$$
K_{c}=2 \cdot \int_{0}^{\frac{\pi}{2}} T(\alpha) \cdot \cos (\alpha) \cdot \sin (\alpha) \cdot d \alpha
$$

\section{Results}

The following sections will present the results of the neutral density model developed in this study. Neutral densities from a single aperture and a NEXT grid will be presented, and near- and far-field models will be compared. The neutral density downstream of a NEXT ion thruster will be presented with and without neutralizer flow and a vacuum facility background pressure. Finally, the impact of past simplifying assumptions for predicting downstream neutral densities will be assessed. 


\section{A. Downstream Neutral Density From a Single Aperture}

The neutral density surrounding a single aperture is shown in Figure 9 for a NEXT accelerator grid cylindrical aperture. The figure was modeled with Equation (17) and the equations listed in Tables 2 to 4 for the aperture interior and downstream regions. Figure 9 also includes additional equations derived in Reference 30 for the upstream region. The figure shows a depleted density zone immediately upstream of the aperture, and that the neutral density drops rapidly from the upstream region to the downstream region, through the aperture. Figure 10 shows just the neutral density downstream of the aperture. The neutral density drops to less than 10 percent of the upstream value within 1 aperture radius of the downstream surface.

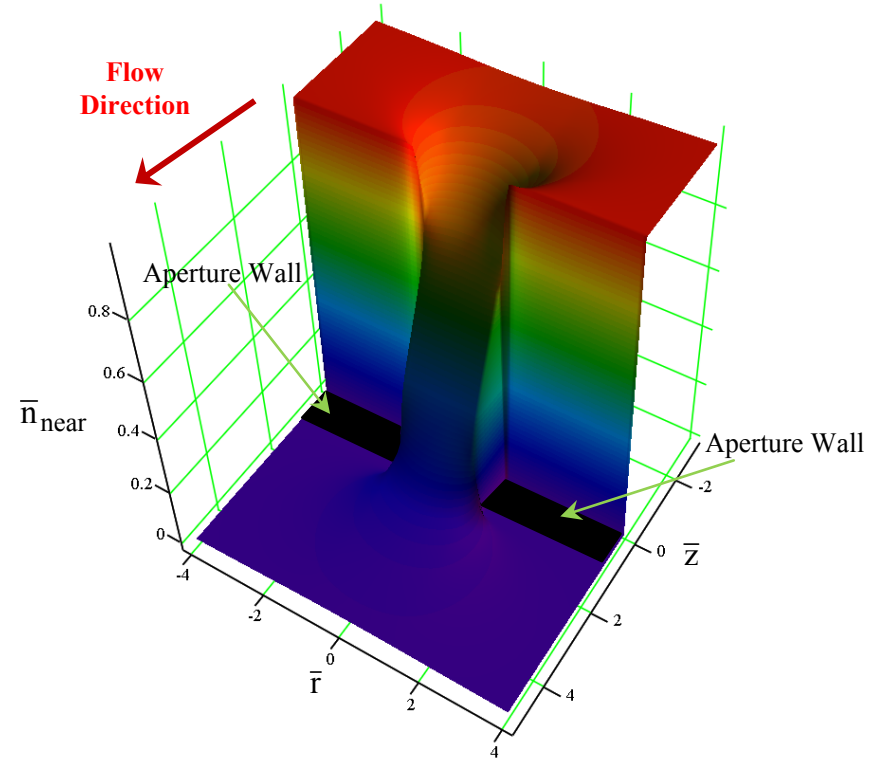

Figure 9.-Neutral density surrounding a single NEXT accelerator aperture.

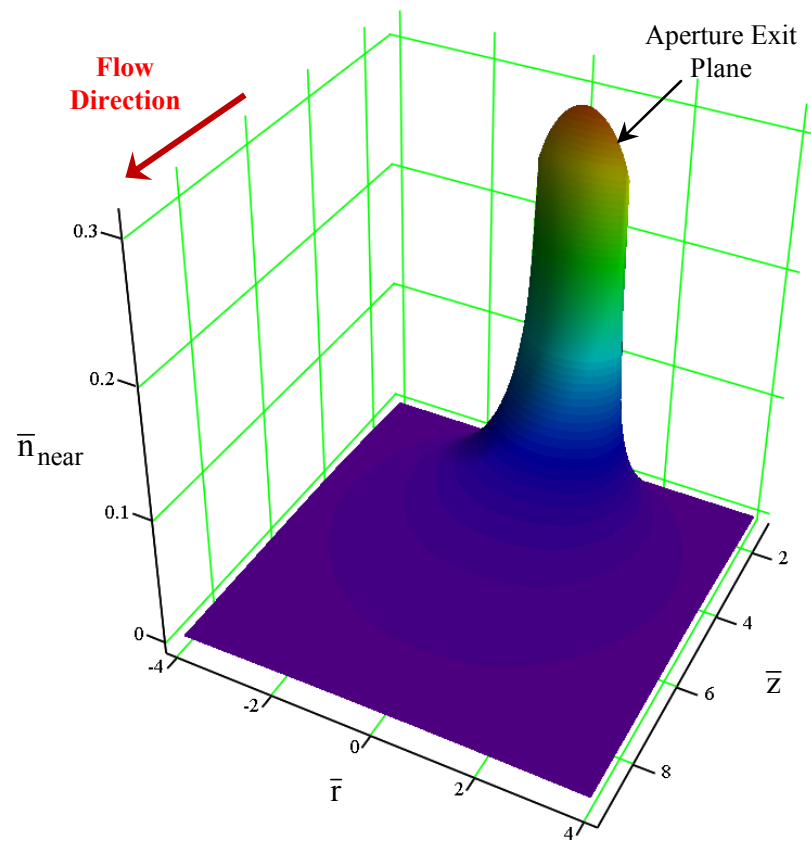

Figure 10.-Downstream neutral density from a single NEXT accelerator gird. 
The far-field non-dimensional neutral density equation (i.e., Eq. (12)) is compared to that calculated with Equation (17) in Figure 11. Here, the neutral density was determined at fixed radial distances from the downstream center of the aperture from 2 to 60 radii while the angle was varied (i.e., a spherical coordinate system was used) to determine angular distributions. The figure illustrates that at increasing distances from the aperture, the far-field angular distribution becomes equal to that of the Equation (17) and that the worst-case error in the far-field equation occurs along the axial centerline of the aperture. Also plotted in Figure 11 is the angular distribution of a simple diffuse assumption (i.e., $\mathrm{T}(\alpha)=1$ ) corrected for the reduced transmission probability due to the aperture walls at 60 radii from the aperture. The diffuse assumption produces a distribution that is more heavily weighted to larger angles and results that range from -36 to 107 percent that of the more rigorous calculation.

Because Equation (17) represents a rigorous solution for downstream neutral density, the far-field equation of Equation (12) was compared to it in Figure 12 to determine the error as a function of non-dimensional radial distance from the downstream aperture center at various angles for a NEXT accelerator grid aperture. The figure shows that maximum far-field equation errors reduce to about 5 percent at about 25 aperture radii downstream for the $0^{\circ}$ case, but within 9 aperture radii for the remaining angles. This figure demonstrates that the far-field equation will produce accurate results within 9 aperture radii downstream of a NEXT accelerator grid aperture.

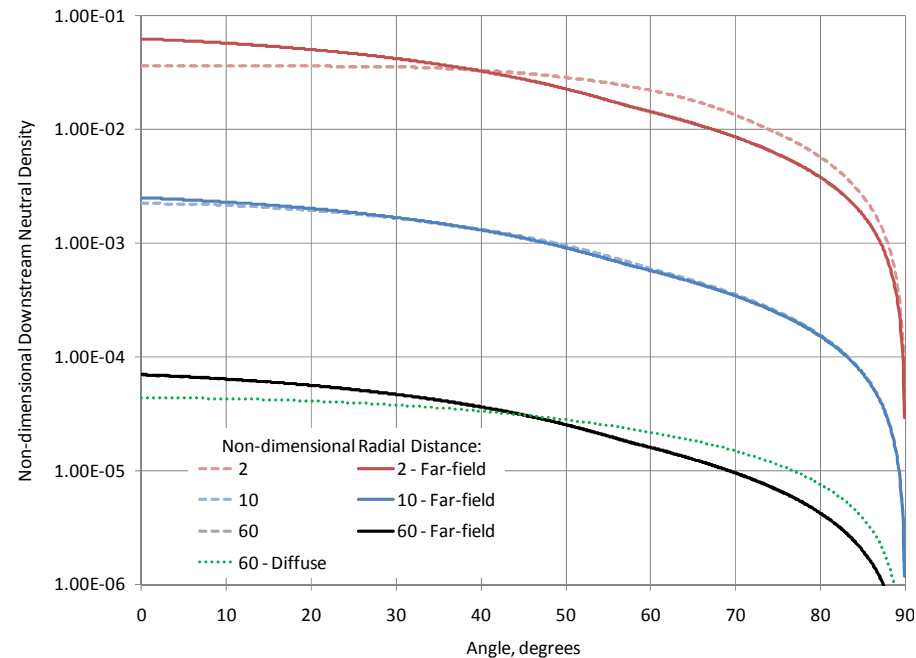

Figure 11.-Non-dimensional neutral density angular distributions for a variety of radial distances in a spherical coordinate system that is centered at the downstream aperture center for a NEXT accelerator aperture. Solid lines were determined from Equation (17) and dashed lines from Equation (12).

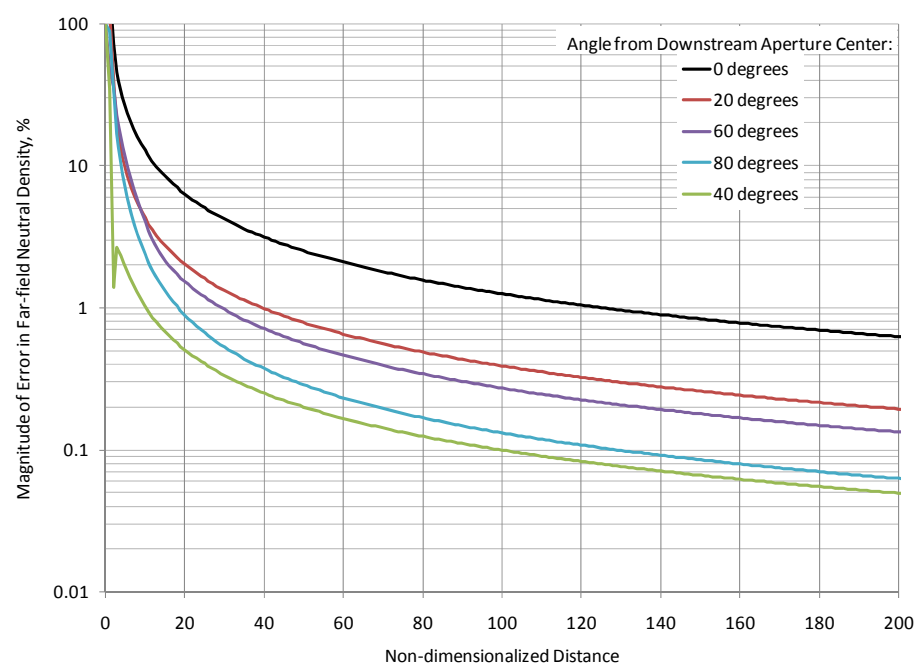

Figure 12.-Far-field error as a function of radial distance at various angles in a spherical coordinate system that is centered at the downstream aperture center for a NEXT accelerator aperture. 


\section{B. Downstream Neutral Density From the Ion Thruster Grids Only}

For this section, only the discharge chamber neutral loss through the grids is modeled. The contributions of the neutralizer and background vacuum facility neutrals are neglected so that near- and far-field comparisons can be made. In addition, the neutral density within the discharge chamber was assumed to be constant, so that $\mathrm{D}(\gamma, \beta)=1$ in Equation (24), and the effect of the upstream screen grid was included (i.e., $\mathrm{F}_{\text {scrn }}=0.93$ ).

The non-dimensional neutral density downstream of a NEXT ion thruster from neutrals escaping through the grid apertures is shown in Figure 13. This was determined using Equation (29), which includes the rigorous calculation of Equation (17) for the downstream neutral density from a single aperture. As the figure illustrates, the neutral density drops rapidly from the ion thruster grids into the downstream region due to the rapid expansion of the neutrals as they exit the accelerator apertures.

Close to the thruster grids, the contribution of adjacent apertures to the downstream neutral density of any given aperture can be examined. The neutral density downstream of the center aperture of a NEXT accelerator grid (i.e., $r=0$ ) from Equation (29) and the adjacent webbing (i.e., $r=1_{c c} / 2$ ) is compared in Figure 14 to that from a single aperture from Equation (17). The number densities at $r=0$ and $r=1_{c c} / 2$ converge within 3 aperture radii for the multiple aperture case and within 6 radii for the single aperture case. More important, however, are the downstream magnitudes. The multiple apertures of the grids increase the downstream neutral density of the center aperture by 10x compared to that of the single aperture at only about 6.5 aperture radii from the accelerator grid. This demonstrates the significant contribution of adjacent apertures to the downstream neutral density of any given aperture for the NEXT ion thruster grids.

Figure 15 also demonstrates another simplifying assumption that can be employed for the NEXT grids. Equation (27) neglects the contribution of individual apertures by treating the entire domed grid surface as a neutralemitting surface whose angular distribution is corrected for the "beaming" effects of the cylindrical apertures. Because differences between the densities of Equations (27) and (29) decrease to 1 percent within about 5 accelerator aperture radii from the accelerator grid, such a simplifying assumption also produces accurate neutral densities within about $3 \mathrm{~mm}$ of the NEXT thruster's accelerator grid. Because of the ease of using this equation and the accuracy of the results, Equation (27) will be used for the remainder of this study.

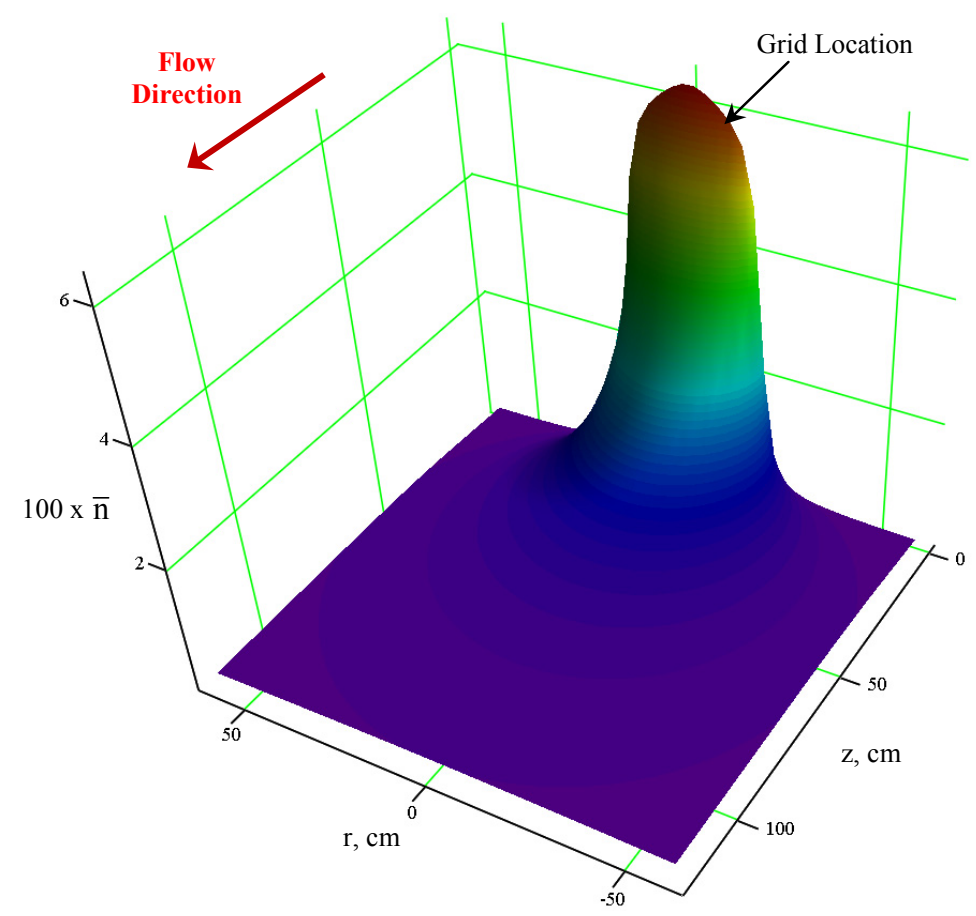

Figure 13.-Non-dimensional neutral density downstream of a NEXT ion thruster. The neutral density within the discharge chamber is assumed constant. 


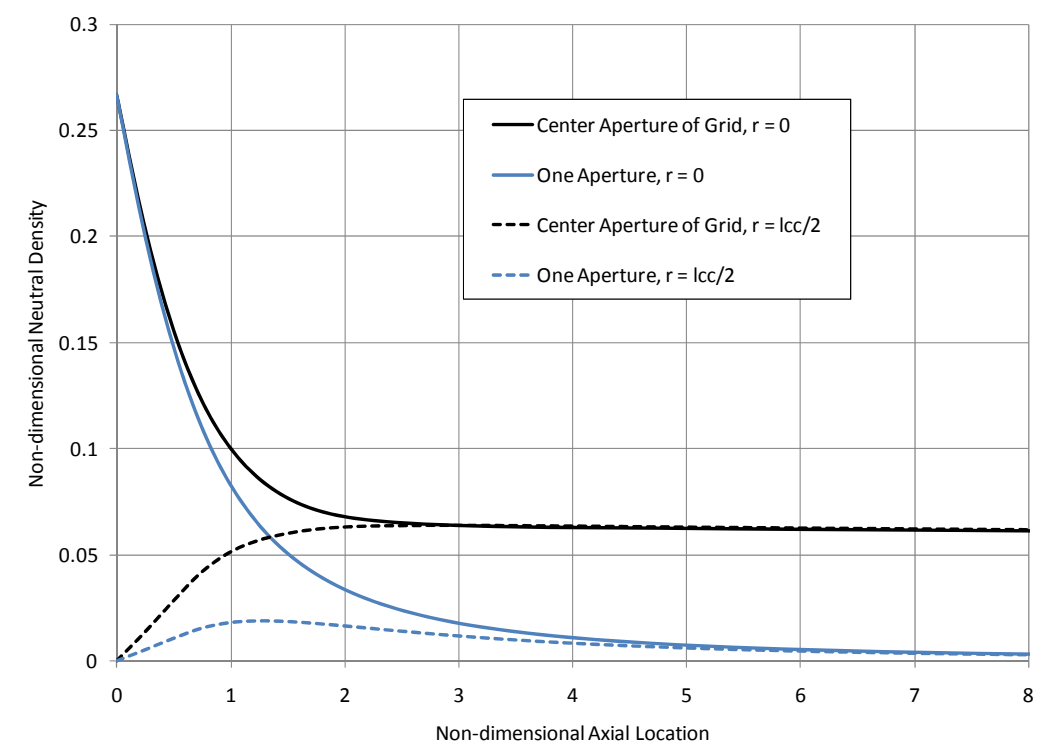

Figure 14.-Non-dimensional downstream neutral density from a NEXT ion thruster along the grid centerline and at $r=I_{c c} / 2$ comparing the effect of the multiple apertures of a grid to that of a single aperture.

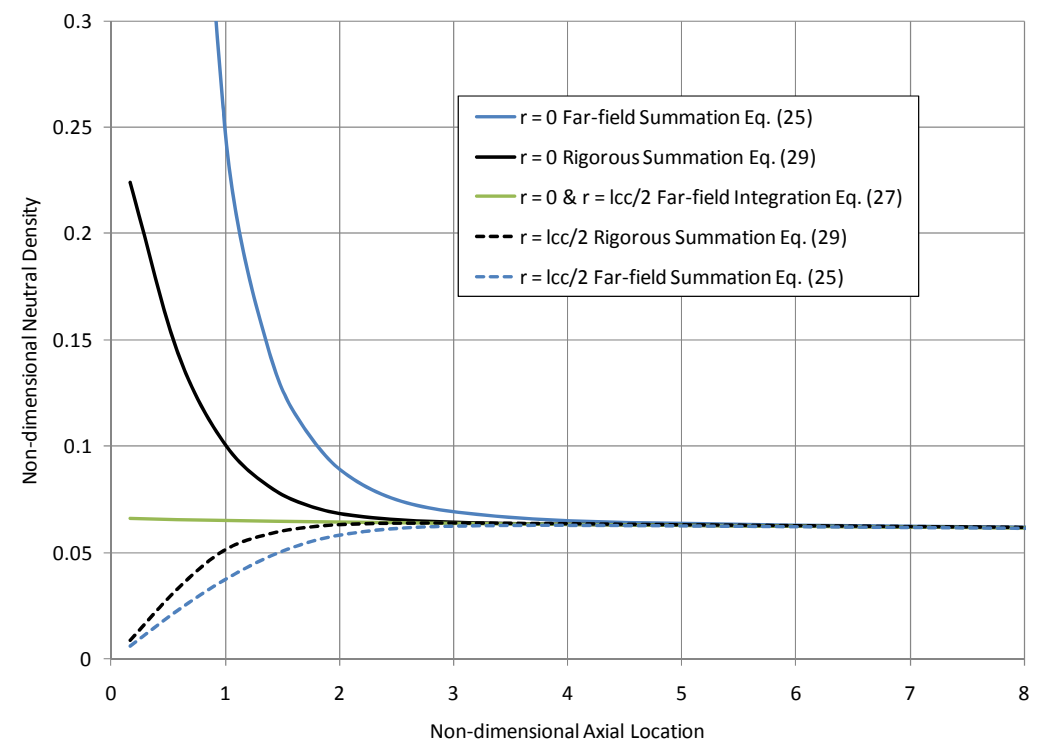

Figure 15.-Non-dimensional downstream neutral density from a NEXT ion thruster along the grid centerline and at $r=\mathrm{I}_{\mathrm{cc}} / 2$ using

Equations (25), (27), and (29).

Although Equation (17) represents a rigorous solution for downstream neutral density of a single aperture, its use for determining the downstream densities from a perforated grid in Equation (29) can be cumbersome and computationally costly. However, the far-field assumptions used for solving the downstream neutral density of a perforated grid in Equations (25) and (27) are significantly less cumbersome to use and can be computed more quickly. So, although Equations (25) and (27) are accurate in the far-field, it would be of value to determine how accurate they are close to a NEXT ion thruster. Figure 15 compares the results of Equations (25) and (27) to Equation (29) along the centerline of the grids and at a radius of $1_{c c} / 2$ (i.e., between two apertures). As the figure illustrates, the far-field results converge rapidly onto the more rigorous results of Equation (29). In fact, differences reduce to 1 percent within about 5 accelerator aperture radii from the accelerator grid. Because the NEXT accelerator aperture diameter is so small in comparison to the overall grid size, the far-field assumptions used in Equations (25) and (27) produce accurate neutral densities within about $3 \mathrm{~mm}$ of the NEXT thruster's accelerator grid. 


\section{Total Downstream Neutral Density}

The contributions of the neutralizer and background vacuum facility neutrals are included in this section. For all of the following calculations, a NEXT ion thruster geometry was assumed. In addition, the neutral density within the discharge chamber was assumed to be constant so that $\mathrm{D}(\gamma, \beta)=1$ in Equation (24), and the effect of the upstream screen grid was included (i.e., $\mathrm{F}_{\text {scrn }}=0.93$ ).

The effect of neutrals from the neutralizer on the downstream neutral density for an NEXT ion thruster operating at full power is shown in Figure 16, which excludes the effect of background vacuum facility neutrals and therefore represents operation in space. For a NEXT thruster operating at full power, the neutral loss rates are estimated to be $7.05 \mathrm{sccm}$ for the discharge chamber and $2.8 \mathrm{sccm}$ for the neutralizer. The discharge chamber neutral temperature was assumed to be $300{ }^{\circ} \mathrm{C}$ while the neutralizer neutral temperature was assumed to be $1100{ }^{\circ} \mathrm{C}$ (Ref. 36). The figure illustrates the impact of the neutralizer neutrals on the downstream neutral density. The high neutral density surrounding the neutralizer was due to neutrals being distributed across such a small keeper orifice area compared to that of the grid area. Figure 17 plots the non-dimensional neutral density as a function of axial location with and without neutralizer neutrals at radial locations of $18 \mathrm{~cm}$ near and opposite the neutralizer (i.e., $\beta=0^{\circ}$ and $180^{\circ}$, respectively). The $18 \mathrm{~cm}$ radial location was selected because it is the edge of the perforate grid radius. As expected, the neutralizer does not contribute to the density upstream of the neutralizer tip because there is no direct line-ofsight there. However, beyond that, the density increases by as much as 68 percent close to the neutralizer. Further downstream, the neutralizer's off-center effect is minimized, but the density is still about 22 percent larger because of the neutralizer's contribution.

The effect of background neutrals from the vacuum facility on the downstream neutral density for an NEXT ion thruster operating at full power is shown in Figure 18. Here, the background pressure was set to $6.7 \times 10^{-3} \mathrm{~Pa}$ $\left(5 \times 10^{-6}\right.$ torr) with a background neutral temperature of $20^{\circ} \mathrm{C}$. The effect of neutralizer neutrals was included in this figure using the same assumptions as for Figure 16. The figure illustrates the significant impact of the facility neutrals on the downstream neutral density. Figure 17 includes the effect of vacuum facility neutrals on the nondimensional neutral density as a function of axial location at radial locations of $18 \mathrm{~cm}$ near and opposite the neutralizer. Although the contributions of the grid and neutralizer are significant close to them, the vacuum facility contribution represents the vast majority of the neutral density further away.

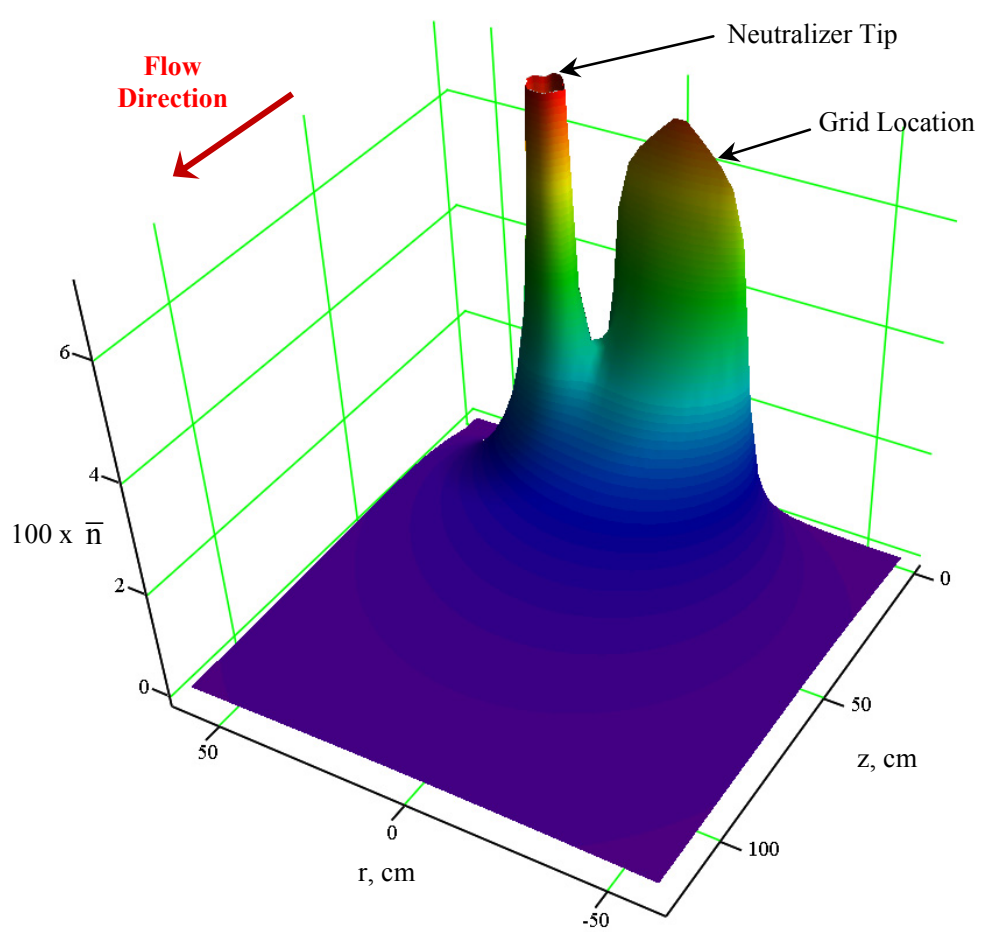

Figure 16.-Non-dimensional neutral density downstream of a NEXT ion thruster operating at full power in space. The neutral density within the discharge chamber was assumed constant and the neutral loss rate from the neutralizer was $2.8 \mathrm{sccm}$. 


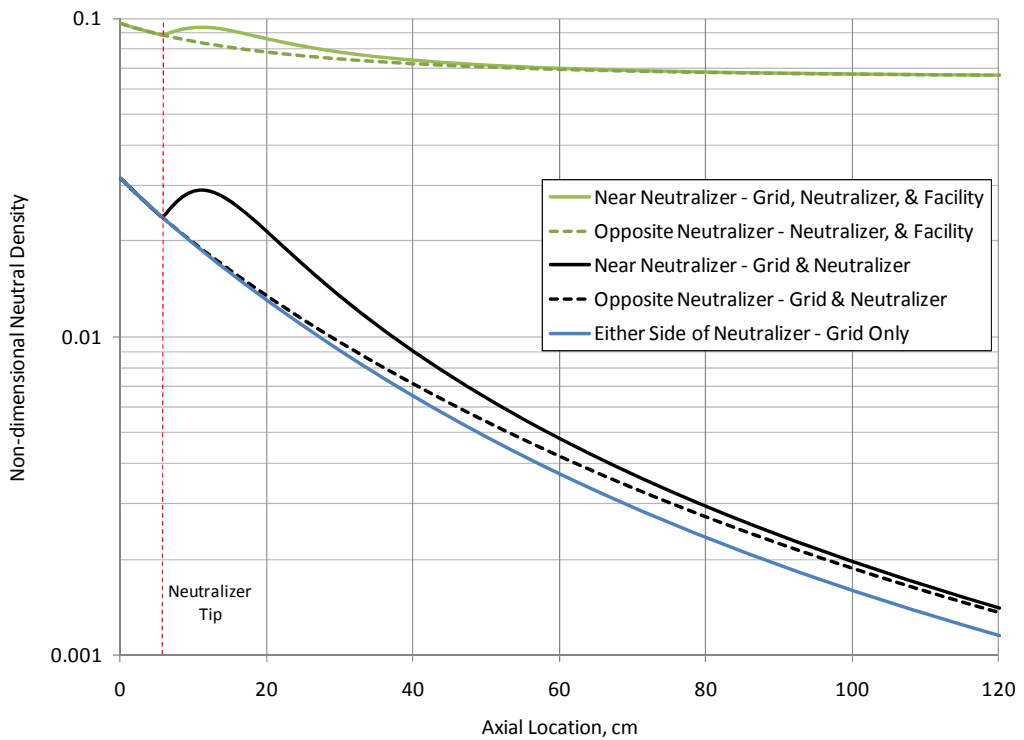

Figure 17.-Non-dimensional neutral density downstream of a NEXT ion thruster operating at full power with and without neutralizer and vacuum facility contributions. The two radial locations shown include $r=18 \mathrm{~cm}$ in the direction of the neutralizer (i.e., $\beta=0^{\circ}$ ) and $r=18 \mathrm{~cm}$ opposite the neutralizer (i.e., $\beta=180^{\circ}$ ). The neutralizer tip is located at about $\mathrm{z}=6 \mathrm{~cm}$.

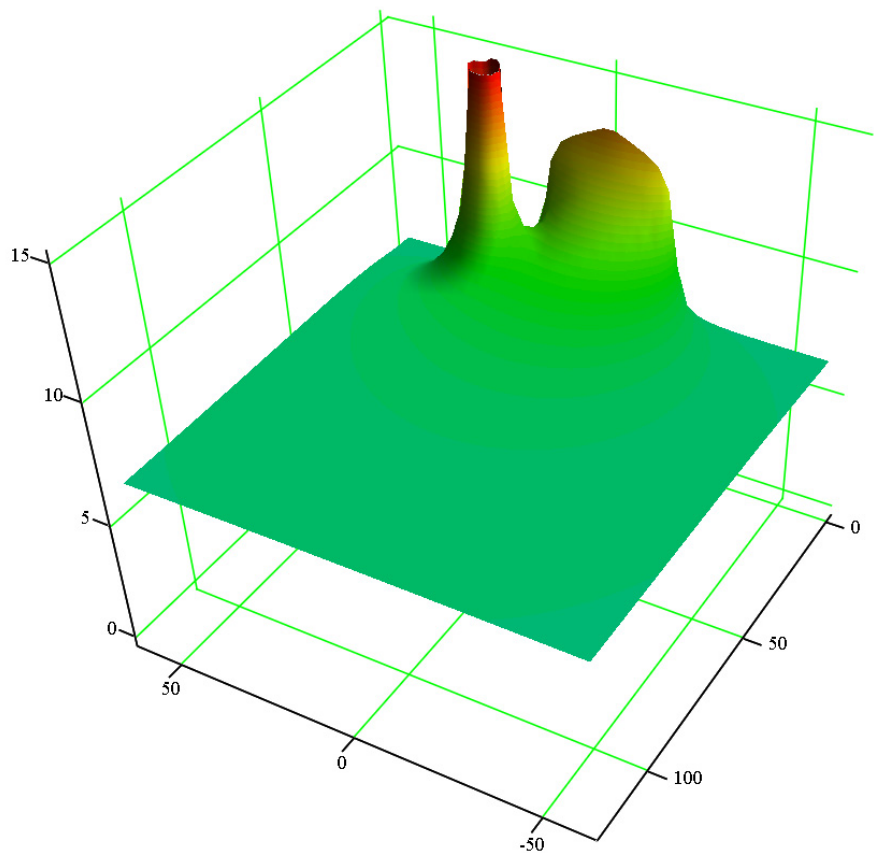

Figure 18.-Non-dimensional neutral density downstream of a NEXT ion thruster operating at full power with vacuum facility neutrals. The neutral density within the discharge chamber was assumed constant and the neutral loss rate from the neutralizer was $2.8 \mathrm{sccm}$. Vacuum facility background pressure was set to $6.7 \times 10^{-3} \mathrm{~Pa}\left(5 \times 10^{-6}\right.$ torr $)$. 


\section{Assessment of Past Assumptions}

This section will assess some past simplifying assumptions that were made to more easily determine the downstream neutral density. These simplifying assumptions include neglecting the effect of neutralizer neutrals, neglecting the "beaming" effect of the cylindrical aperture walls, and assuming a flat grid. All of these assumptions will be examined with a NEXT ion thruster operating at full power.

The impact of the neutralizer was already assessed in the prior section (see Fig. 17). It was shown that neglecting the neutralizer's contribution to the downstream neutral density would lead to a neutral density that is 22 percent lower than actual in the far-field for a NEXT thruster operating at full power. The impact of neglecting the "beaming" effect of the aperture walls is illustrated in Figure 19 along the grid centerline. In this figure, the effects of neutralizer and vacuum facility background neutrals were ignored to facilitate direct comparisons. And although neutrals were assumed to exit an aperture diffusely, the upstream neutral density was set equal to that where the "beaming" effect is included (i.e., the baseline case). The figure shows that the neutral density begins higher than the baseline case close to the grids because the diffuse angular distribution contributes more neutrals to the grid centerline close to the grid. But further away, this same effect leads to lower neutral densities as the neutrals expand more rapidly. So, ignoring the "beaming" effect of the aperture walls leads to an overestimation of 14 percent close to the grid and an under-estimation that approaches 30 percent in the far-field.

The impact of assuming a flat grid is also illustrated in Figure 19 along the grid centerline. The upstream neutral density was set equal to that of the domed grid case, and the "beaming" effect of the aperture walls is included. The figure shows that the neutral density is always higher than the baseline case because the flat grid collimates the outgoing neutrals. The flat grid assumption led to neutral density overestimations along the grid centerline of as large as 29 percent in the near-field and 14 percent in the far-field.

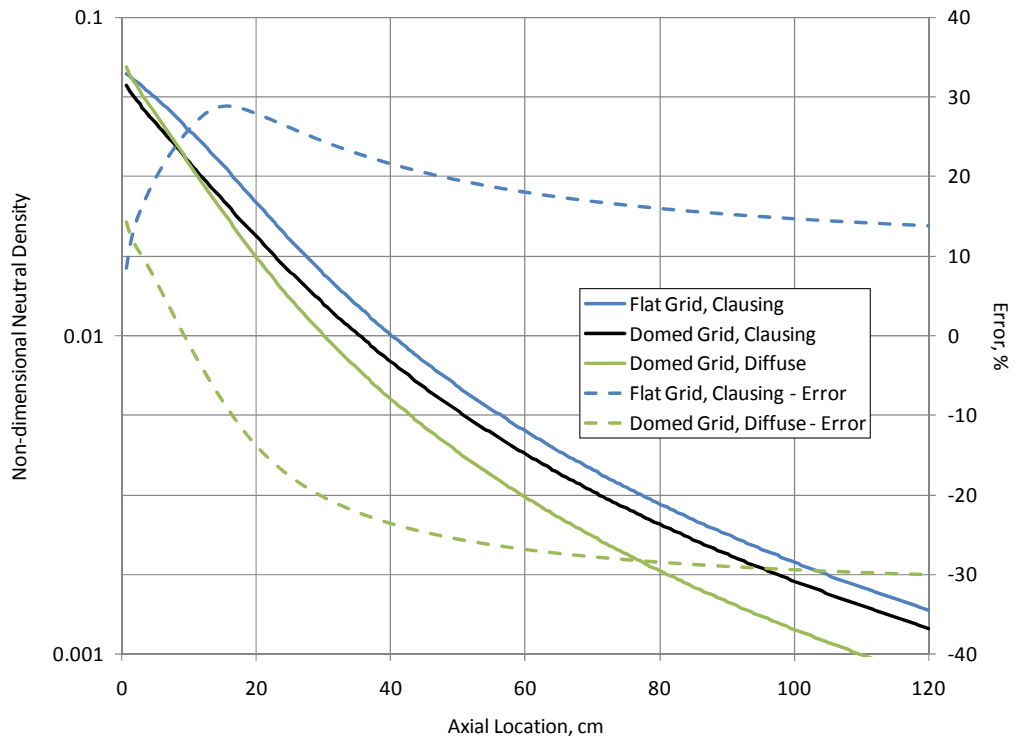

Figure 19.-Non-dimensional downstream neutral density and errors as a function of axial location along the grid centerline for: a domed NEXT grid that includes the "beaming" effect of the aperture walls (Clausing, or the baseline case); a domed NEXT grid that excludes the "beaming" effect of the aperture walls (diffuse assumption); and a flat grid that includes the "beaming" effect of the aperture walls. 


\section{Conclusions}

The details of a model for determining the neutral density downstream of a gridded ion thruster were presented. A rigorous examination of the possible sources of neutrals emanating from and surrounding a NEXT ion thruster concluded that the most significant contributors to the downstream neutral density included discharge chamber neutrals escaping through the perforated grids, neutrals escaping from the neutralizer, and vacuum facility background neutrals. Because ion thrusters were shown to operate in the free molecular flow regime, each neutral density source was modeled separately and the results added together.

For the neutral flux through the grids, near- and far-field equations were presented for rigorously determining the neutral density downstream of a cylindrical aperture. These equations included the "beaming" effect of the aperture walls. These equations were subsequently integrated into a spherically-domed convex grid geometry with a hexagonal array of apertures for determining neutral densities downstream of the ion thruster grids. The neutrals escaping from an off-center neutralizer were also modeled assuming diffuse neutral emission from the neutralizer keeper orifice. Finally, the effect of the surrounding vacuum facility neutrals was included and assumed to be constant.

The model was then used to predict the neutral density downstream of a NEXT ion thruster with and without neutralizer flow and a vacuum facility background pressure. Individual aperture results showed that far-field equation errors reduced to about 5 percent within 9 aperture radii, indicating that the far-field equation will produce accurate results close to a NEXT accelerator grid aperture. The neutral density from the NEXT thruster grids as a function of axial distance was found to decrease rapidly due to the rapid expansion of the neutrals as they exit the accelerator apertures. Because the NEXT accelerator aperture diameter is so small in comparison to the overall grid size, the far-field equations were shown to produce accurate neutral densities within about $3 \mathrm{~mm}$ of the NEXT thruster's accelerator grid. One of these far-field equations neglected the contribution of individual apertures by treating the entire domed grid surface as a neutral-emitting surface whose angular distribution is corrected for the "beaming" effects of the cylindrical apertures. Because this equation was least cumbersome and computationally efficient, it was used for the remainder of the study.

The impacts of the neutralizer neutral loss rate and the surrounding vacuum facility neutrals were separately assessed for a NEXT ion thruster operating at full power. Beyond the neutralizer, the density increased by as much as 68 percent at a radial location of $18 \mathrm{~cm}$ close to the neutralizer. Further downstream, the neutralizer's off-center effect was minimized, but the density was still about 22 percent larger because of the neutralizer's contribution. Proper modeling of charge-exchange production in the ion beam requires incorporating the effects of neutralizer neutral efflux. Vacuum facility effects were assessed at a background pressure set to $6.7 \times 10^{-3} \mathrm{~Pa}\left(5 \times 10^{-6}\right.$ torr). Although the contributions of the grid and neutralizer were still significant close to them, the vacuum facility contribution represented the vast majority of the neutral density further away.

The impact of past simplifying assumptions for predicting downstream neutral densities were also assessed for a NEXT ion thruster. Neglecting the "beaming" effect of the aperture walls along the grid centerline led to an overestimation of neutral density by 14 percent close to the grid and an under-estimation that approached 30 percent in the far-field. Assuming a flat grid led to neutral density overestimations along the grid centerline of as large as 29 percent in the near-field and 14 percent in the far-field.

\section{References}

1. Rawlin, V.K., et al., “An Ion Propulsion System for NASA’s Deep Space Missions,” AIAA Paper 99-4612, September 1999.

2. Polk, J.E., et al., "Demonstration of the NSTAR Ion Propulsion System on the Deep Space One Mission," IEPC Paper 2001-075, October 2001.

3. Brophy, J.R., et al., "The DS1 Hyper-extended Mission,” AIAA Paper 2002-3673, July 2002.

4. Brophy, J.R., et al., "Implementation of the Dawn Ion Propulsion System," AIAA Paper 2005-4071, July 2005.

5. Brophy, J.R., et al., "Dawn Ion Propulsion System: Initial Checkout After Launch," Journal of Propulsion and Power, vol. 25, no. 6, November-December 2009, pp. 1189-1202.

6. Patterson, M.J. and Benson, S.W., "NEXT Ion Propulsion System Development Status and Performance," AIAA Paper 2007-5199, July 2007.

7. Benson, S.W. and Patterson, M.J., "NEXT Ion Propulsion System Progress Towards Technology Readiness," AIAA Paper 2008-5285, July 2008. 
8. Pollard, J.E., et al., "Spatially-Resolved Beam Current and Charge-State Distributions for the NEXT Ion Engine," To be presented at the 46th AIAA/ASME/SAE/ASEE Joint Propulsion Conference in July 2010.

9. Miller, J.S., et al., "Xenon Charge Exchange Cross Sections for Electrostatic Thruster Models," Journal of Applied Physics, vol. 91, no. 3, 2002, pp. 984-991.

10. Clausing, P., "The Formation of Beams in Molecular Streaming," Z. Physik, vol. 66, 1930, pp. 471-476.

11. Dayton, B.B., "Gas Flow Patterns at Entrance and Exit of Cylindrical Tubes," National Symposium on Vacuum Technology Transactions, Pergamon Press, New York, 1956, pp. 5-11.

12. Reynolds, T.W. and Richley, E.A., "Distribution of Neutral Propellant from Electric Thrusters onto Spacecraft Components," NASA Technical Note D-5576, December 1969.

13. Hall, D.F., Newnam, B.E., and Womack, J.R., "Electrostatic Rocket Exhaust Effects on Solar-Electric Spacecraft Subsystems," AIAA Paper 1969-271, March 1969.

14. Samanta Roy, R.I., et al., "A Hybrid Particle-in-Cell/Fluid Model of Ion Thruster Plumes," AIAA Paper 19940421, January 1994.

15. Samanta Roy, R.I., Hastings, D.E., and Gatsonis, N.A., "Ion Thruster Plume Modeling for Backflow Contamination," Journal of Spacecraft and Rockets, vol. 33, no. 4, July-August 1996, pp. 525-534.

16. Samanta Roy, R.I. and Hastings, D.E., "Three-Dimensional Modeling of Dual Ion-Thruster Plumes for Spacecraft Contamination," Journal of Spacecraft and Rockets, vol. 33, no. 4, July-August 1996, pp. 519-524.

17. Samanta Roy, R.I., Hastings, D.E., and Gatsonis, N.A., "Numerical Study of Spacecraft Contamination and Interactions by Ion-Thruster Effluents," Journal of Spacecraft and Rockets, vol. 33, no. 4, July-August 1996, pp. 535-542.

18. Wang, J., et al., "Deep Space One Investigations of Ion Propulsion Plasma Interactions: Overview and Initial Results," AIAA Paper 1999-2971, June 1999.

19. Wang, J., Brinza, D., and Young, M., "Modeling of Ion Propulsion Plasma Environment for Deep Space 1," AIAA Paper 2000-3528, July 2000.

20. Wang, J., Cao, Y., and Kafafy, R., "Electric Propulsion Plume Modeling Using Parallel Supercomputers," AIAA Paper 2006-3559, June 2006.

21. Cho, M., et al., "Interaction Between High Voltage Solar Array and Ion Thruster Plasma," IEPC Paper 2003053, March 2003.

22. Davis, V.A., et al., "Ion Engine Generated Charge Exchange Environment: Comparison Between NSTAR Flight Data and Numerical Simulations," AIAA Paper 2000-3539, July 2000.

23. Boyd, I.D., et al., "Monte Carlo Simulation of Neutral Xenon Flows in Electric Propulsion Devices," Journal of Propulsion and Power, vol. 14, no. 6, November-December 1998, pp. 1009-1015.

24. VanGilder, D.B., Font, G.I., and Boyd, I.D., "Hybrid Monte Carlo Particle-in-Cell Simulation of an Ion Thruster Plume," Journal of Propulsion and Power, vol. 15, no. 4, August 1999, pp. 530-538.

25. Nishida, M., et al., "DCMC-PIC Analysis of a Plume from a Small Ion Engine," IEPC Paper 2001-110, October 2001.

26. Fergason, S.D., "Ion Thruster Plume Simulation Using Clustered PC Workstations," AIAA Paper 2005-966, January 2005.

27. Kameyama, I., Monheiser, J.M., and Wilbur, P.J., “A Numerical Model of Thruster-Exhaust Plumes,” IEPC Paper 1997-180, August 1997.

28. Mandell, M.J., et al., "Modeling the NEXT Multithruster Array Test With Nascap-2k," IEEE Transactions on Plasma Science, vol. 36, no. 5, October 2005, pp. 2309-2318.

29. Kuharski, R.A., et al., "Ion Engine Neutralizer Erosion in Lab and Space," AIAA Paper 2005-3880, July 2005.

30. Soulas, G.C., "Neutral Flux and Density Surrounding a Cylindrical Aperture in the Free Molecular Flow Regime," to be published as a NASA Technical Memorandum.

31. Soulas, G.C., et al., "NEXT Single String Integration Test Results," AIAA Paper 2009-4816, August 2009.

32. O'Hanlon, J.F., A User's Guide to Vacuum Technology, John Wiley \& Sons, Inc., New York, 1980, pp. 25-36.

33. Mikellidis, I.G., et al., "Neutralizer Hollow Cathode Simulations and Validations with Experiments," AIAA Paper 2009-5196, August 2009.

34. Mikellidis, I.G., Private Communication, June 11, 2010.

35. Gombosi, T.I., Gas Kinetic Theory, Cambridge University Press, Cambridge, 1994, pp. 18-35.

36. Van Noord, J.L., "NEXT Ion Thruster Thermal Model,” AIAA Paper 2007-5218, July 2007. 


\begin{tabular}{|c|c|c|}
\hline \multicolumn{2}{|c|}{ REPORT DOCUMENTATION PAGE } & $\begin{array}{l}\text { Form Approved } \\
\text { OMB No. 0704-0188 }\end{array}$ \\
\hline \multicolumn{3}{|c|}{ 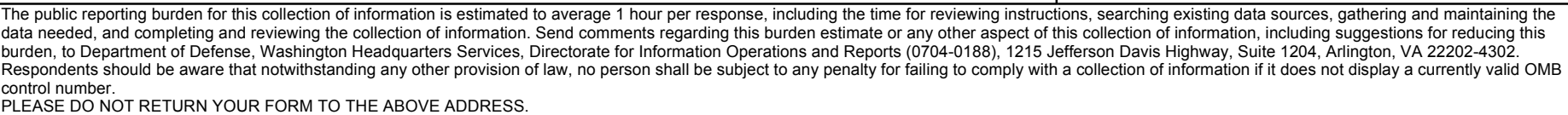 } \\
\hline $\begin{array}{l}\text { 1. REPORT DATE (DD-MM-YYYY) } \\
01-12-2010\end{array}$ & $\begin{array}{l}\text { 2. REPORT TYPE } \\
\text { Technical Memorandum }\end{array}$ & 3. DATES COVERED (From - To) \\
\hline \multirow{3}{*}{\multicolumn{2}{|c|}{$\begin{array}{l}\text { 4. TITLE AND SUBTITLE } \\
\text { Modeling Neutral Densities Downstream of a Gridded Ion Thruster }\end{array}$}} & 5a. CONTRACT NUMBER \\
\hline & & 5b. GRANT NUMBER \\
\hline & & 5c. PROGRAM ELEMENT NUMBER \\
\hline \multirow{3}{*}{\multicolumn{2}{|c|}{$\begin{array}{l}\text { 6. AUTHOR(S) } \\
\text { Soulas, George, C. }\end{array}$}} & 5d. PROJECT NUMBER \\
\hline & & 5e. TASK NUMBER \\
\hline & & $\begin{array}{l}\text { 5f. WORK UNIT NUMBER } \\
\text { WBS } 346620.04 .08 .02 .02 .01\end{array}$ \\
\hline \multicolumn{2}{|c|}{$\begin{array}{l}\text { 7. PERFORMING ORGANIZATION NAME(S) AND ADDRESS(ES) } \\
\text { National Aeronautics and Space Administration } \\
\text { John H. Glenn Research Center at Lewis Field } \\
\text { Cleveland, Ohio 44135-3191 }\end{array}$} & $\begin{array}{l}\text { 8. PERFORMING ORGANIZATION } \\
\text { REPORT NUMBER } \\
\text { E-17507 }\end{array}$ \\
\hline \multirow{2}{*}{\multicolumn{2}{|c|}{$\begin{array}{l}\text { 9. SPONSORING/MONITORING AGENCY NAME(S) AND ADDRESS(ES) } \\
\text { National Aeronautics and Space Administration } \\
\text { Washington, DC 20546-0001 }\end{array}$}} & $\begin{array}{l}\text { 10. SPONSORING/MONITOR'S } \\
\text { ACRONYM(S) } \\
\text { NASA }\end{array}$ \\
\hline & & $\begin{array}{l}\text { 11. SPONSORING/MONITORING } \\
\text { REPORT NUMBER } \\
\text { NASA/TM-2010-216930 }\end{array}$ \\
\hline \multicolumn{3}{|c|}{$\begin{array}{l}\text { 12. DISTRIBUTION/AVAILABILITY STATEMENT } \\
\text { Unclassified-Unlimited } \\
\text { Subject Category: } 20 \\
\text { Available electronically at http://gltrs.grc.nasa.gov } \\
\text { This publication is available from the NASA Center for AeroSpace Information, 443-757-5802 }\end{array}$} \\
\hline
\end{tabular}

\section{SUPPLEMENTARY NOTES}

\section{ABSTRACT}

The details of a model for determining the neutral density downstream of a gridded ion thruster are presented. An investigation of the possible sources of neutrals emanating from and surrounding a NEXT ion thruster determined that the most significant contributors to the downstream neutral density include discharge chamber neutrals escaping through the perforated grids, neutrals escaping from the neutralizer, and vacuum facility background neutrals. For the neutral flux through the grids, near- and far-field equations are presented for rigorously determining the neutral density downstream of a cylindrical aperture. These equations are integrated into a spherically-domed convex grid geometry with a hexagonal array of apertures for determining neutral densities downstream of the ion thruster grids. The neutrals escaping from an off-center neutralizer are also modeled assuming diffuse neutral emission from the neutralizer keeper orifice. Finally, the effect of the surrounding vacuum facility neutrals is included and assumed to be constant. The model is used to predict the neutral density downstream of a NEXT ion thruster with and without neutralizer flow and a vacuum facility background pressure. The impacts of past simplifying assumptions for predicting downstream neutral densities are also examined for a NEXT ion thruster.

\section{SUBJECT TERMS}

Ion thruster; Ion engine; Free molecular flow; Neutral density

\begin{tabular}{|c|c|c|c|c|c|}
\hline \multicolumn{3}{|c|}{ 16. SECURITY CLASSIFICATION OF: } & \multirow{2}{*}{$\begin{array}{l}\text { 17. LIMITATION OF } \\
\text { ABSTRACT } \\
\text { UU }\end{array}$} & \multirow{2}{*}{$\begin{array}{l}\text { 18. NUMBER } \\
\text { OF } \\
\text { PAGES } \\
37\end{array}$} & \multirow{2}{*}{$\begin{array}{l}\text { 19a. NAME OF RESPONSIBLE PERSON } \\
\text { STI Help Desk (email:help@sti.nasa.gov) } \\
\text { 19b. TELEPHONE NUMBER (include area code) } \\
\text { 443-757-5802 }\end{array}$} \\
\hline $\begin{array}{l}\text { a. REPORT } \\
\text { U }\end{array}$ & $\begin{array}{l}\text { b. ABSTRACT } \\
U\end{array}$ & $\begin{array}{l}\text { c. THIS } \\
\text { PAGE } \\
\text { U }\end{array}$ & & & \\
\hline
\end{tabular}



